\title{
Built environmental correlates of older adults' total physical activity and walking: a systematic review and meta-analysis
}

\author{
David W. Barnett ${ }^{1}$, Anthony Barnett ${ }^{1}$, Andrea Nathan ${ }^{1}$, Jelle Van Cauwenberg ${ }^{2,3}$, Ester Cerin ${ }^{1,4,5^{*}}$ (D)
}

and on behalf of the Council on Environment and Physical Activity (CEPA) - Older Adults working group

\begin{abstract}
Background: Identifying attributes of the built environment associated with health-enhancing levels of physical activity (PA) in older adults ( $\geq 65$ years old) has the potential to inform interventions supporting healthy and active ageing. The aim of this study was to first systematically review and quantify findings on built environmental correlates of older adults' PA, and second, investigate differences by type of PA and environmental attribute measurement.

Methods: One hundred articles from peer-reviewed and grey literature examining built environmental attributes related to total PA met inclusion criteria and relevant information was extracted. Findings were meta-analysed and weighted by article quality and sample size and then stratified by PA and environmental measurement method. Associations $(p<.05)$ were found in relation to 26 individual built environmental attributes across six categories (walkability, residential density/urbanisation, street connectivity, access to/availability of destinations and services, infrastructure and streetscape, and safety) and total PA and walking specifically. Reported individual- and environmental-level moderators were also examined.
\end{abstract}

Results: Positive environmental correlates of PA, ranked by strength of evidence, were: walkability $(p<.001)$, safety from crime $(p<.001)$, overall access to destinations and services $(p<.001)$, recreational facilities $(p<.001)$, parks/ public open space $(p=.002)$ and shops/commercial destinations $(p=.006)$, greenery and aesthetically pleasing scenery $(p=.004)$, walk-friendly infrastructure $(p=.009)$, and access to public transport $(p=.016)$. There were 26 individual differences in the number of significant associations when the type of PA and environmental measurement method was considered. No consistent moderating effects on the association between built environmental attributes and PA were found.

Conclusions: Safe, walkable, and aesthetically pleasing neighbourhoods, with access to overall and specific destinations and services positively influenced older adults' PA participation. However, when considering the environmental attributes that were sufficiently studied (i.e., in $\geq 5$ separate findings), the strength of evidence of associations of specific categories of environment attributes with PA differed across PA and environmental measurement types. Future research should be mindful of these differences in findings and identify the underlying mechanisms. Higher quality research is also needed.

Keywords: Older adults, Built environment, Physical activity, Walking, Correlates, Systematic review, Meta-analysis

\footnotetext{
* Correspondence: ester.cerin@acu.edu.au

${ }^{1}$ Institute for Health and Ageing, Australian Catholic University, Level 6, 215

Spring Street, Melbourne, VIC 3000, Australia

${ }^{4}$ School of Public Health, The University of Hong Kong, 7 Sassoon Road,

Pokfulam, Hong Kong, Special Administrative Region, China

Full list of author information is available at the end of the article
} 


\section{Background}

Worldwide, the proportion of older adults (65 years or older) is forecast to grow exponentially from 524 million in 2010 to approximately 1.5 billion individuals by 2050 [1]. This will pose a major economic challenge for societies globally, given the healthcare expenditure associated with individuals experiencing age-related chronic diseases [1, 2]. Evidence suggests that regular engagement in PA is particularly important for healthy ageing. For example, it reduces the risk of coronary heart disease, some cancers, type 2 diabetes, depression, cognitive impairment and social isolation [3, 4]. Older adults worldwide, however, are often inactive [4-7]. Thus, it is important to identify modifiable factors with a high level of reach that may help increase total PA in this age group. As it is ultimately the overall dose of PA that confers benefit/detriment upon health [8], irrespective of the domain/s in which it was accrued, it is important to focus on factors contributing to total PA. Furthermore, walking is the most prevalent and preferred form of PA in older adults [9], low-risk and beneficial to health and can contribute substantially to daily energy expenditure [10]. Hence, this review will focus on total PA and total walking.

Socio-ecological models posit that PA behaviour is shaped by complex and dynamic interrelations between individual, social, and environmental factors [11, 12]. The built environment offers substantial public health potential, due to people being regularly exposed to it across their life span. Understanding the impact of built environmental attributes on older adults' PA is particularly pertinent as their diminished physical capacity makes them more vulnerable to the detrimental effects of physically challenging environments (e.g., inclines, uneven surfaces, absence of walk-friendly infrastructure) on PA [13]. In turn, this may lead to less venturing outside of the home due to fear of falls [14]. However, a previous review of the built environment and older adults' PA identified no consistent correlates [15].

One postulated reason for the lack of consistent significant associations between environmental correlates and PA was the relative 'western' bias of the reviewed research $-68 \%$ of the 31 articles reviewed by Van Cauwenberg and colleagues were from North America alone [15]. This is an important limitation since homogenously low-density western cities lack environmental variability potentially resulting in the underestimation of the strength of associations between the built environment and PA. Also, western cities differ from the built environments of Africa, Asia, and South America, limiting the generalizability of findings [16-18]. In consideration of the recent growing evidence from nonwestern countries (e.g., [19-25]), an update of the literature was necessary.
Further reasons for inconsistent findings on the associations between the built environment and PA may relate to the methodologies of the systematic reviews and/or the studies being reviewed. For example, Gebel and colleagues [26] recommended that systematic reviews should: a) consider article/study quality in the synthesis of findings; and b) include relevant data from grey literature. Also, small sample sizes, a large variety of built environmental exposures and PA outcomes [27, 28], and the inappropriate categorisation of continuous variables [29] in examined studies may have contributed to inconsistent findings. To date, no systematic review on the built environment and total PA has considered these issues.

A synthesis of evidence would also need to distinguish between findings based on objective- and self-report measures of exposures (environmental attributes) and outcomes (PA). Self-report measures are more likely to be influenced by culture [30, 31] and, thus, yield different findings across geographical locations due to measurement rather than substantive reasons. Also, perceptions of the local environment may not accurately represent the 'real' environment $[32,33]$. Indeed, associations of PA with objective and perceived measures of the built environment tend to differ $[34,35]$. This does not necessarily mean that one type of measurement is better than the other, however, as perceived environmental measures may be more closely associated with PA than objective alternatives [27], a consideration of these differences would help better inform policies and interventions.

With regard to measurement of total PA, objective PA measures are considered to provide more valid assessments of intensity, duration, and frequency of PA than subjective alternatives [36]. They are also less likely to be influenced by cultural biases [30]. Additionally, differences in environment-PA associations between selfreported and objectively-measured PA have previously been reported in adults [37]. This indicates that there is a need for a synthesis of findings on built environment correlates of total PA by type of PA assessment (objective and self-reported).

Therefore, this systematic review aimed to provide a timely, robust overview of studies that investigated associations of built environmental attributes and estimates of total PA, including total walking. This included addressing some key methodological limitations of previous reviews by stratifying findings by measurement methods (objective and self-reported) and applying a meta-analytic procedure. The latter incorporated study quality data to more robustly quantify the direction of associations between the built environment and older adults' PA [27] and assisted the formulation of objective conclusions based on statistical theory rather than on subjective criteria (e.g., defining $>50 \%$ of significant 
positive associations as convincing evidence of a positive association between a specific environment characteristic and PA).

\section{Methods}

This systematic review and meta-analysis was registered in PROSPERO (Registration no. CRD42016051227 [38]) in November 2016.

\section{Literature search strategy}

Our systematic literature search followed Preferred Reporting Items for Systematic Reviews and MetaAnalyses (PRISMA) guidelines [39] and was an extended update of Van Cauwenberg et al.'s 2011 review [15] including additional electronic databases and search terms to account for grey literature, experimental research, a greater variety of built environmental attributes and older adults' PA. Systematic searches were performed in the following electronic databases (September - November 2016): Cinahl, PubMed, Scopus, SPORTDiscus, TRIS, and Web of Science. An example of the complete search terms syntax (used in PubMed) is presented in the resulting PRISMA flowchart (Fig. 1). All electronic database searches used the same search terms and syntax. However, filters varied depending on available options in each database. Manual searches were then undertaken of previously published systematic reviews, meta-analyses and authors' personal archives. The websites of Active Living Research, SUSTRANS, the National Institute for Health and Clinical Excellence, Heart Foundation, and Open Grey were also searched for grey literature (e.g., unpublished studies, theses and reports).

\section{Selection criteria}

Article eligibility for inclusion was based on the following criteria: (1) published in English between 1st January 2000 and 3rd September 2016; (2) quantitative study; (3) study with a cross-sectional, longitudinal or quasi-experimental design; (4) a sample with a mean age $\geq 65$ years; (5) investigated the association between any objective or perceived attribute of the built environment and objectively measured or self-reported PA and/or walking that was not specific to a single PA domain only; (6) did not exclusively focus on clinical populations (e.g., overweight, disabled or institutionalised participants); and (7) did not investigate associations between PA and the built environment with an ill-defined aggregated environmental measure that, for example, combined two weakly correlated attributes such as access to/availability of recreational facilities and traffic/ pedestrian safety.

Three reviewers independently screened articles for eligibility criteria by title and then by abstract. If abstracts met the inclusion criteria, the article text was independently read by two reviewers, and a decision for inclusion made accordingly. The reviewers discussed and resolved any disputed inclusions. Post article inclusion, first authors' publication histories and eligible articles' reference lists were screened for additional eligible articles. One hundred articles were eligible for inclusion in this review (Fig. 1).

\section{Data extraction}

Two reviewers independently extracted all relevant information from eligible papers and cross-checked each other's work upon completion. Any disputes were resolved in consultation with a third member of the team. A table (Additional file 1) was then constructed containing the following data: study name (if any), first author and publication year; participant information - sample size, study setting (e.g., urban or rural), mean age, percentage of females, study response rate, community dwellers or not, geographical location; study design -

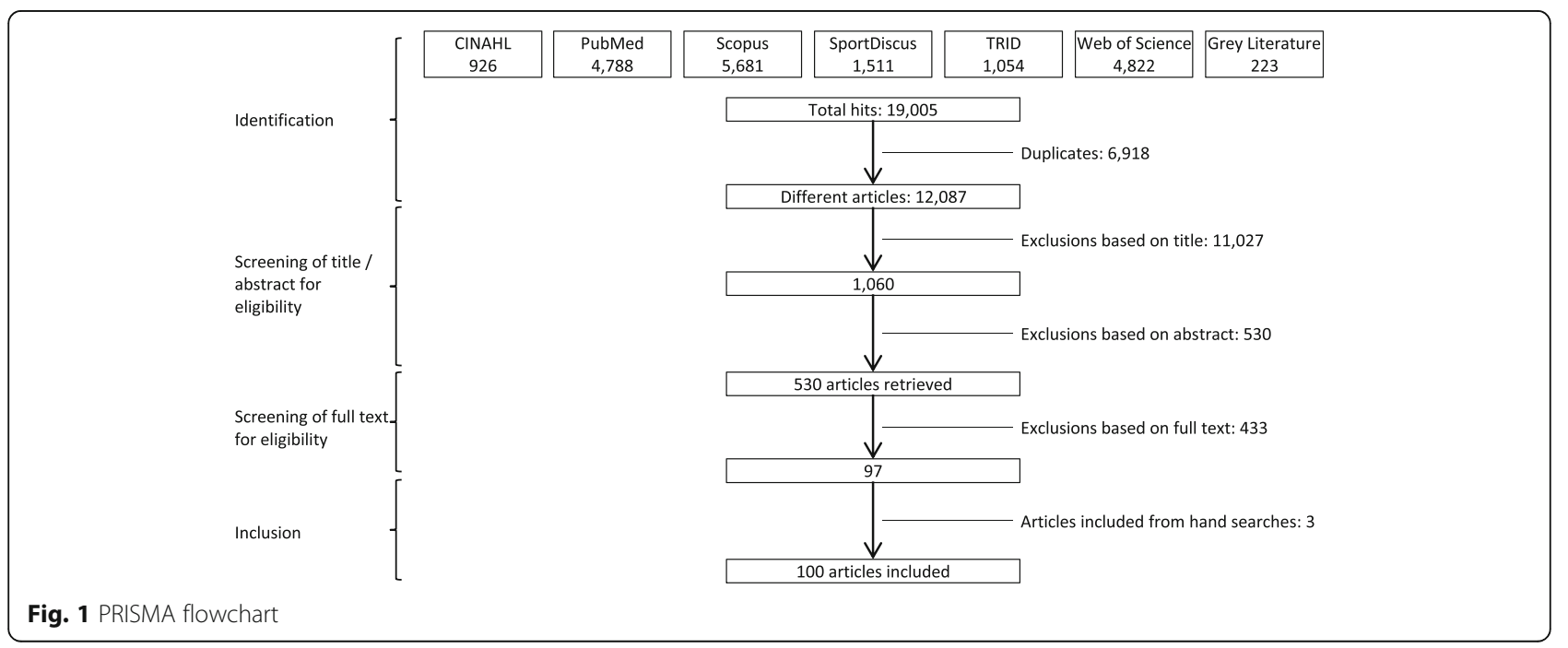


sampling method for clusters (areas or neighbourhoods) and individuals, stratification of recruitment site by environmental attribute/s (if any), neighbourhood definition (if any); list of covariates; PA outcome information - type of measurement (objective or self-reported), instrument or device used and whether or not it was validated, how outcome measures were operationalised (e.g., continuously or categorically); environmental exposure information - type of measurement (objective or perceived), name of measure, environmental attributes as named in study and category of environmental attribute according to the classification used in this review (see below); moderator information (if any); analytical approach information; findings; and additional comments important for the assessment or interpretation of the study (if any).

In this review, the variable "Total PA" represents all (combined) PA outcomes relevant to this review and extracted from the selected articles. These include the PA outcomes reported in the selected articles as "Total PA", "Total MVPA" and "Total walking". "Total PA" was then stratified into objective and self-report PA, congruent with study aims. Total walking was also considered separately for reasons aforementioned. Built environmental attributes were categorised according to an expanded list of factors included in the Neighbourhood Environment Walkability Scale (NEWS), which is the most frequently used neighbourhood environment questionnaire internationally $[40,41]$ (Table 1 ). The detailed list of measures included under each category of environmental attributes can be found in Supplementary Table S1 (Additional file 1).

\section{Coding and quantification of associations}

Following the protocol used by Van Cauwenberg and colleagues in their earlier systematic review [15], associations between built environmental attributes and PA outcomes were categorised as statistically significantly positive $(\mathrm{P})$, significantly negative $(\mathrm{N})$, or not statistically significant (Ø). When available, preference was given to findings within articles that adjusted for sociodemographic covariates and self-selection (i.e., factors that may affect neighbourhood choice and subsequent PA level, for example, preference for PA resources [42]). Often, one article reported multiple environmental attributes that were coded under the same environmental category (e.g., 'absence of litter' and 'presence of trees' would both fall under the common category of 'greenery and aesthetically pleasing scenery'). Similarly, one article may have reported multiple PA outcomes related to the same environmental attribute (e.g., 'total walking' and 'total PA' with 'crime/personal safety'). Four distinct findings would be extracted from these two examples. We then cross-examined other articles from the same dataset (e.g., Senior Neighborhood Quality of Life Study (SNQLS) [43-48]) to avoid duplication of extracted data.

\section{Quantification of buffer effects and/or moderators}

Findings from studies reporting associations for a given combination of environmental attribute and PA outcome for multiple environmental buffer sizes or values of a moderator were assigned fractional weights totalling 1.0 (per study). Associations from studies reporting on multiple buffer sizes were each assigned a fractional weight equal to 1 divided by the number of buffer sizes. For example, Nathan and colleagues examined associations for two buffer sizes ( $400 \mathrm{~m}$ and $800 \mathrm{~m})$. They found a nil association for $400 \mathrm{~m}$ buffers around the home between access to social infrastructure and total walking and a positive one for $800 \mathrm{~m}$ buffers [49]. In this case, a resulting score of 0.5 nil ( $400 \mathrm{~m}$ buffer) and 0.5 positive associations $(800 \mathrm{~m}$ buffer) was recorded. For studies that examined moderator effects, associations were reported as main effects only if the findings across all examined values of the moderator were consistent in direction and statistical significance. When this did not occur, weights were assigned for each examined value of the moderator dependent upon the (approximate) proportion of the total sample represented by the subgroup of participants. For example, Jefferis and colleagues found a positive association between access to social and leisure activities for males and a nil association for females [50]. Since males represented $65 \%$ of the total sample, a fractional weight of 0.65 was assigned to the positive association and a 0.35 weight for the nil association (females). For studies that used a continuous measure of moderators, associations recorded at the average value of the moderator were assigned a weight of 0.60 , while those above and below the mean were each assigned a weight of 0.20 (i.e., \pm 1 standard deviation (SD)). This follows the logic that, if data are normally distributed, $\approx 20 \%$ of values would fall below and 20\% above 1SD (accounting for some uncertainty around the value of the moderator at $\pm 1 \mathrm{SD}$ ). When an association was moderated by numerous factors, weights were assigned according to the aforementioned procedure and, again, with all fractional weights totalling 1.0.

\section{Article quality and sample size assessment}

A checklist for article quality assessment was developed based on ten set criteria [with a maximum total quality score of 9] (Additional file 2): (1) study design [score: crosssectional $=0$, longitudinal $=1$, quasi-experimental $=2] ;(2)$ study areas or participant recruitment stratified by key environmental attributes [yes $=1$, no $=0$ ]; (3) adequate participant response rate $(\geq 60 \%)$ [51] or evidence of a representative sample [yes $=1$, no $=0$ ]; (4) outcome measures valid and reliable based on published metric properties of 
Table 1 Characteristics of selected articles $(N=100)$

\begin{tabular}{|c|c|c|c|}
\hline Characteristic & $\begin{array}{l}\text { Number } \\
\text { of articles }\end{array}$ & $\%$ & Article reference \\
\hline \multicolumn{4}{|l|}{ Study design ${ }^{a}$} \\
\hline Cross-sectional & 95 & 94 & {$[19-25,32,43-50,53,54,59,60,65,67-80,87,92,93,100,118-173]$} \\
\hline Longitudinal & 5 & 5 & [61-65] \\
\hline Quasi-experimental & 1 & 1 & [66] \\
\hline \multicolumn{4}{|l|}{ Geographical area: continent } \\
\hline Africa & 1 & 1 & [25] \\
\hline Asia & 16 & 16 & {$[19-22,60,73,75,80,124,139,142,146,160,164,169,173]$} \\
\hline Europe & 22 & 22 & $\begin{array}{l}{[50,66,74,79,87,119,120,123,129,136,137,147,148,152,154,156,} \\
157,162,163,165,166,170]\end{array}$ \\
\hline North America & 46 & 46 & $\begin{array}{l}{[32,43-48,53,54,61-65,67-70,76,78,92,93,125-127,130-135,138,} \\
140,141,143,144,149-151,155,158,159,161,167,168,172]\end{array}$ \\
\hline Oceania & 13 & 13 & {$[49,59,71,72,77,100,118,121,122,128,145,153,171]$} \\
\hline South America & 2 & 2 & {$[23,24]$} \\
\hline \multicolumn{4}{|l|}{ Geographical area: country } \\
\hline Australia & 13 & 13 & {$[49,59,71,72,77,100,118,121,122,128,145,153,171]$} \\
\hline Belgium & 2 & 2 & {$[74,170]$} \\
\hline Brazil & 1 & 1 & [23] \\
\hline Canada & 10 & 10 & {$[54,61,62,78,125-127,135,138,172]$} \\
\hline China & 1 & 1 & [80] \\
\hline Colombia & 1 & 1 & [24] \\
\hline Czech Republic, Poland, \& Slovakia (pooled analysis) & 1 & 1 & [154] \\
\hline Hong Kong, China & 2 & 2 & {$[73,124]$} \\
\hline Iceland & 1 & 1 & [119] \\
\hline Iran & 1 & 1 & [146] \\
\hline Ireland & 2 & 2 & {$[147,152]$} \\
\hline Japan & 7 & 7 & {$[19-22,160,164,169]$} \\
\hline Lithuania & 1 & 1 & [120] \\
\hline Malaysia & 1 & 1 & [139] \\
\hline Netherlands & 4 & 4 & {$[123,136,137,166]$} \\
\hline Norway & 1 & 1 & [157] \\
\hline Singapore & 1 & 1 & [142] \\
\hline South Africa & 1 & 1 & [25] \\
\hline South Korea & 2 & 2 & {$[75,173]$} \\
\hline Thailand & 1 & 1 & [60] \\
\hline United Kingdom & 10 & 10 & {$[50,66,79,87,129,148,156,162,163,165]$} \\
\hline United States of America & 36 & 36 & $\begin{array}{l}{[32,43-48,53,63-65,67-70,76,92,93,130-134,140,141,143,144,} \\
149-151,155,158,159,161,167,168]\end{array}$ \\
\hline \multicolumn{4}{|l|}{ Geographical setting } \\
\hline Urban & 56 & 56 & $\begin{array}{l}{[23-25,32,43-48,50,53,59,61-64,66,71,72,74,80,87,92,93,100} \\
120-122,124-127,129-131,133,135-138,142,144,146,149,153 \\
156-158,161,164,165,167,170,172]\end{array}$ \\
\hline Rural & 3 & 3 & [67-69] \\
\hline Mixed & 32 & 32 & $\begin{array}{l}{[19,21,22,49,54,60,75,76,79,118-120,123,128,132,134,139,} \\
143,145,147,148,150,152,155,159,160,162,163,166,169,171,173]\end{array}$ \\
\hline Not reported & 9 & 9 & {$[65,70,77,78,140,141,151,154,168]$} \\
\hline
\end{tabular}


Table 1 Characteristics of selected articles $(N=100)$ (Continued)

\begin{tabular}{|c|c|c|c|}
\hline \multicolumn{4}{|l|}{ Sample size ${ }^{b}$} \\
\hline$\leq 100$ & 9 & 9 & {$[19,25,53,61,66,118,127,135,161]$} \\
\hline $101-300$ & 27 & 27 & $\begin{array}{l}{[32,43,53,59,60,67,69,76,87,119,120,122,123,129,132,133,} \\
140-142,146,150,156,162-166]\end{array}$ \\
\hline $301-500$ & 23 & 23 & $\begin{array}{l}{[23,47,63,64,68,71-75,93,100,121,124,126,131,134,153,154,} \\
160,167,169,170]\end{array}$ \\
\hline $501-1000$ & 16 & 16 & {$[44-46,48,62,78,79,92,125,128,138,144,147,148,158,159]$} \\
\hline $1001-2500$ & 11 & 11 & {$[20,22,24,50,54,77,130,151,155,172,173]$} \\
\hline$>2500$ & 16 & 16 & {$[21,49,54,65,70,80,136,137,139,143,145,149,152,157,168,171]$} \\
\hline \multicolumn{4}{|l|}{ Study with multiple articles } \\
\hline Active Living Study & 3 & 3 & {$[71,72,153]$} \\
\hline BEPAS Seniors & 2 & 2 & {$[74,170]$} \\
\hline Great Britain older adults 1 & 2 & 2 & {$[162,163]$} \\
\hline Health and Wellbeing Surveillance System & 2 & 2 & {$[49,171]$} \\
\hline LL-FDI study (Late-Life Function and Disability Instrument) & 2 & 2 & {$[132,150]$} \\
\hline Melbourne older adults study 1 & 2 & 2 & {$[121,122]$} \\
\hline Netherlands Housing Survey (WoON) & 2 & 2 & {$[136,137]$} \\
\hline Nurses' Health Study & 2 & 2 & {$[70,168]$} \\
\hline PACS (Physical Activity Cohort Scotland) & 2 & 2 & {$[79,148]$} \\
\hline Project OPAL (Older People Active Living) & 3 & 3 & {$[87,129,165]$} \\
\hline SHAPE (Senior Health and Physical Exercise) & 4 & 4 & {$[32,63,92,93]$} \\
\hline SNQLS (Senior Neighborhood Quality of Life Study) & 6 & 6 & [43-48] \\
\hline TILDA (The Irish Longitudinal Study on Ageing) & 2 & 2 & {$[147,152]$} \\
\hline VoisiNuAge & 2 & 2 & {$[62,138]$} \\
\hline Single publication (named study) & 33 & 33 & $\begin{array}{l}{[21,50,54,59,61,64-66,73,77,78,80,100,124,128,130,133-135,139,} \\
140,143-145,149,155,157-159,166,169,172,173]\end{array}$ \\
\hline Single publication (unnamed study) & 31 & 31 & $\begin{array}{l}{[19,20,22-25,53,60,67-69,75,76,118-120,123,125-127,131,141,} \\
142,146,151,154,156,160,161,164,167]\end{array}$ \\
\hline \multicolumn{4}{|l|}{ Neighbourhood recruitment stratification ${ }^{a}$} \\
\hline Environmental attributes & 57 & 57 & $\begin{array}{l}{[19,21-25,32,44-50,54,60,63,66,68,71-76,78-80,87,92,118,119} \\
123,124,126,129,130,134,135,139,146-148,151,153,155,159,160 \\
162-166,168,170-172]\end{array}$ \\
\hline Urbanisation & 22 & 22 & $\begin{array}{l}{[19,21,22,49,54,60,68,75,78,80,118,119,123,134,139,155,159,} \\
160,166,168,171,172]\end{array}$ \\
\hline Area-level socio-economic status & 6 & 6 & {$[23,25,87,129,151,165]$} \\
\hline Area-level socio-economic status \& walkability & 12 & 12 & {$[44-48,73,74,124,126,135,146,170]$} \\
\hline Area-level socio-economic status \& urbanisation & 10 & 10 & {$[50,63,76,79,92,130,147,148,162,163]$} \\
\hline Walkability & 4 & 4 & {$[32,71,72,153]$} \\
\hline Streetscape & 2 & 2 & {$[66,164]$} \\
\hline Demographics & 31 & 31 & $\begin{array}{l}{[20-22,50,62,64,69,70,79,119,121,122,132-134,136-138,141-144,} \\
148,150,151,155,156,161-163,173]\end{array}$ \\
\hline None & 21 & 21 & $\begin{array}{l}{[43,53,59,61,65,67,77,93,100,120,125,128,131,140,145,149,154,} \\
157,158,167,169]\end{array}$ \\
\hline
\end{tabular}

Neighbourhood definition ${ }^{\mathrm{a}}$

Objective

Administrative/census area/postal code 
Table 1 Characteristics of selected articles $(N=100)$ (Continued)

\begin{tabular}{|c|c|c|c|}
\hline \multicolumn{4}{|l|}{ Buffer (crow-fly or road-network) } \\
\hline$\leq 250 \mathrm{~m}$ & 3 & 3 & {$[21,64,171]$} \\
\hline $300 \mathrm{~m}$ & 1 & 1 & [123] \\
\hline $400-500 \mathrm{~m}$ & 16 & 16 & {$[21,24,44,46-49,59,64,72,73,93,135,153,159,171]$} \\
\hline $800-1000 \mathrm{~m}$ & 15 & 15 & {$[21,49,59,63,64,73,92,93,130,132,135,155,161,168,171]$} \\
\hline$>1000 \mathrm{~m}$ & 3 & 3 & {$[161,168,171]$} \\
\hline Variable/not fixed & 4 & 4 & {$[32,135,151,164]$} \\
\hline Retirement village & 3 & 3 & {$[43,72,153]$} \\
\hline Unknown (not reported) & 3 & 3 & {$[53,62,128]$} \\
\hline \multicolumn{4}{|l|}{ Perceived } \\
\hline 10-20 min walk from home & 24 & 24 & $\begin{array}{l}{[20,22,23,44-46,48,60,71,72,75,79,100,121,122,124,126,131,132,} \\
141,143,150,159,169]\end{array}$ \\
\hline Other participant delineation & 22 & 22 & $\begin{array}{l}{[24,25,32,50,61,62,67,69,76,78,87,120,125,129,133,140,147,151,} \\
152,154,165,167]\end{array}$ \\
\hline Retirement village & 2 & 2 & {$[71,153]$} \\
\hline Unknown (not reported) & 6 & 6 & {$[63,77,92,134,144,156]$} \\
\hline \multicolumn{4}{|c|}{ Physical activity outcome by type of measurement and its operationalisation ${ }^{a}$} \\
\hline \multicolumn{4}{|l|}{ Total PA (all PA outcomes from all articles) } \\
\hline Continuous outcome & 59 & 55.1 & $\begin{array}{l}{[19,21,43-48,54,59,60,62,63,65-67,69,71,73,74,79,80,87,92,93,} \\
118,119,121,123-125,127,129,131,132,134-138,140-144,147-151, \\
155,160,161,164-166,170,173]\end{array}$ \\
\hline Categorical outcome & 48 & 44.9 & $\begin{array}{l}{[20,22-25,32,49,50,53,54,61,64,65,68,70,72,75-78,80,93,100,} \\
120,122,124,126,128,130,133,135,139,144,146,152-154, \\
156-159,162,163,167-169,171,172]\end{array}$ \\
\hline Objective PA & 28 & 27.2 & \\
\hline Continuous outcome & 23 & & {$[19,43-48,59,73,74,79,118,127,129,132,135,141,148,150,164-166,170]$} \\
\hline Categorical outcome & 5 & & {$[25,50,61,72,135,153]$} \\
\hline Self-reported PA & 75 & 73.8 & \\
\hline Continuous outcome & 37 & & $\begin{array}{l}{[19,21,54,60,62,63,65-67,69,71,73,80,87,92,93,119,121,123-125,} \\
131,134,136-138,140-144,147,149,151,155,160,161,173]\end{array}$ \\
\hline Categorical outcome & 45 & & $\begin{array}{l}{[20,22-25,32,49,53,54,64,65,68,70,72,75-78,80,93,100,120,122,} \\
124,126,128,130,133,139,144,146,152-154,156-159,162,163 \\
167-169,171,172]\end{array}$ \\
\hline Total PA (as detailed in article) & 31 & 27.2 & \\
\hline Objective PA & 8 & 8 & \\
\hline Continuous outcome & 8 & 8 & {$[48,79,129,135,148,150,164,166]$} \\
\hline Categorical outcome & 0 & 0 & \\
\hline Self-reported PA & 23 & 23 & \\
\hline Continuous outcome & 19 & 19 & $\begin{array}{l}{[19,60,65-67,69,73,87,119,121,125,136,137,141,143,147,151,} \\
160,161]\end{array}$ \\
\hline Categorical outcome & 4 & 4 & {$[65,70,126,157]$} \\
\hline Total walking (as detailed in article) & 55 & 48.2 & \\
\hline Objective PA & 9 & 9 & \\
\hline Continuous outcome & 8 & 8 & {$[19,118,127,129,132,135,141,165]$} \\
\hline Categorical outcome & 2 & 2 & {$[61,135]$} \\
\hline Self-reported PA & 47 & 47 & \\
\hline Continuous outcome & 19 & 19 & {$[21,62,63,65,67,71,80,92,93,123,124,131,134,138,142,144,149,155,173]$} \\
\hline Categorical outcome & 32 & 32 & $\begin{array}{l}{[20,22-24,32,49,53,64,65,70,72,75,76,80,93,100,122,124} \\
130,144,146,153,154,158,159,162,163,167-169,171,172]\end{array}$ \\
\hline
\end{tabular}


Table 1 Characteristics of selected articles $(N=100)$ (Continued)

\begin{tabular}{|c|c|c|c|}
\hline Total MVPA (as detailed in article) & 28 & 24.6 & \\
\hline Objective PA & 15 & 15 & \\
\hline Continuous outcome & 11 & 11 & {$[43-48,73,74,129,166,170]$} \\
\hline Categorical outcome & 4 & 4 & {$[25,50,72,153]$} \\
\hline Self-reported PA & 14 & 14 & \\
\hline Continuous outcome & 3 & 3 & {$[54,140,173]$} \\
\hline Categorical outcome & 12 & 12 & {$[25,54,68,77,78,120,128,130,133,139,152,156]$} \\
\hline \multicolumn{4}{|l|}{ Environmental attribute by type of measurement ${ }^{a}$} \\
\hline Objective environment & 49 & 48 & \\
\hline Perceived environment & 53 & 52 & \\
\hline Walkability & 13 & 13 & \\
\hline Objective & 11 & 11 & {$[46,48,72-74,146,153,155,167,171,172]$} \\
\hline Perceived & 2 & 2 & {$[126,141]$} \\
\hline Residential density/urbanisation ${ }^{d}$ & 35 & 35 & \\
\hline Objective & 21 & 21 & $\begin{array}{l}{[19,21,47,54,65,70,73,80,92,118,119,123,128,134,139,148,} \\
158-160,168,173]\end{array}$ \\
\hline Perceived & 15 & 15 & {$[20,22,25,48,76,132,140,145,147,150,152,154,159,162,169]$} \\
\hline Street connectivity $^{d}$ & 24 & 24 & \\
\hline Objective & 10 & 10 & {$[21,24,43,53,73,93,159,161,166,168]$} \\
\hline Perceived & 16 & 16 & {$[20,23,25,48,53,71,76,79,127,132,140,142,150,154,159,170]$} \\
\hline Access to/availability of destinations $\&$ services $^{a}$ & 65 & 65 & \\
\hline Objective & 29 & 29 & \\
\hline Perceived & 45 & 45 & \\
\hline Overall access to destinations $\&$ services $^{d}$ & 24 & 24 & \\
\hline Objective & 6 & 6 & {$[21,53,62,93,135,168]$} \\
\hline Perceived & 21 & 21 & $\begin{array}{l}{[20,23,25,48,50,53,62,67,71,76,87,100,126,127,131,132,} \\
140,141,150,154,159]\end{array}$ \\
\hline Land-use mix — destination diversity $^{d}$ & 16 & 16 & \\
\hline Objective & 8 & 8 & {$[49,72,80,123,135,153,159,161]$} \\
\hline Perceived & 9 & 9 & {$[25,48,67,76,125,132,150,159,170]$} \\
\hline Shops/commercial destinations ${ }^{d}$ & 26 & 26 & \\
\hline Objective & 17 & 17 & {$[32,43,47,49,53,72,73,80,93,135,148,158,159,161,166,168]$} \\
\hline Perceived & 10 & 10 & {$[22,23,32,75,129,141,142,156,165,169]$} \\
\hline Food outlets & 11 & 11 & \\
\hline Objective & 8 & 8 & {$[43,47,49,53,73,135,166,168]$} \\
\hline Perceived & 3 & 3 & {$[23,141,142]$} \\
\hline Government/finance services & 8 & 8 & \\
\hline Objective & 7 & 7 & {$[43,47,49,53,73,135,158]$} \\
\hline Perceived & 1 & 1 & [23] \\
\hline Education & 7 & 7 & \\
\hline Objective & 6 & 6 & {$[21,132,135,158,161,168]$} \\
\hline Perceived & 1 & 1 & [141] \\
\hline Health \& aged care & 10 & 10 & \\
\hline Objective & 8 & 8 & {$[43,49,53,72,135,153,158,166]$} \\
\hline Perceived & 2 & 2 & {$[23,156]$} \\
\hline
\end{tabular}


Table 1 Characteristics of selected articles $(N=100)$ (Continued)

\begin{tabular}{|c|c|c|c|}
\hline Religious & 5 & 5 & \\
\hline Objective & 3 & 3 & {$[43,135,161]$} \\
\hline Perceived & 2 & 2 & {$[23,141]$} \\
\hline Public transport & 18 & 18 & \\
\hline Objective & 8 & 8 & {$[24,47,72,73,80,93,158,166]$} \\
\hline Perceived & 10 & 10 & {$[22,23,48,50,62,68,100,141,156,169]$} \\
\hline Parks/public open space ${ }^{d}$ & 30 & 30 & \\
\hline Objective & 17 & 17 & {$[21,24,32,43,44,48,53,64,73,92,93,124,132,135,151,158,161]$} \\
\hline Perceived & 15 & 15 & {$[23,32,46,66,68,69,75,100,125,141,142,144,151,156,163]$} \\
\hline Recreational facilities & 25 & 25 & \\
\hline Objective & 10 & 10 & {$[43,47,64,72,73,124,132,135,153,168]$} \\
\hline Perceived & 15 & 15 & {$[22,23,46,60,63,68,77,78,92,120,125,142,156,169,170]$} \\
\hline Social recreational facilities & 13 & 13 & \\
\hline Objective & 6 & 6 & {$[43,49,73,135,138,166]$} \\
\hline Perceived & 7 & 7 & {$[23,50,71,141,142,153,156]$} \\
\hline Other destinations & 1 & 1 & \\
\hline Objective & 1 & 1 & [43] \\
\hline Perceived & 0 & 0 & \\
\hline Infrastructure \& streetscape $\mathrm{a}^{\mathrm{a}}$ & 43 & 43 & \\
\hline Objective & 12 & 12 & \\
\hline Perceived & 34 & 34 & \\
\hline Overall cycle/walk-friendly infrastructure & 8 & 8 & \\
\hline Objective & 0 & 0 & \\
\hline Perceived & 9 & 9 & {$[25,48,66,76,127,132,150,154,159]$} \\
\hline Walk-friendly infrastructure & 21 & 21 & \\
\hline Objective & 7 & 7 & {$[43,47,80,93,124,132,161]$} \\
\hline Perceived & 14 & 14 & {$[22,44,53,61,62,68,69,71,100,121,125,142,169,170]$} \\
\hline Cycle-friendly infrastructure & 4 & 4 & \\
\hline Objective & 1 & 1 & [47] \\
\hline Perceived & 3 & 3 & {$[22,125,169]$} \\
\hline No physical environmental barriers (e.g., hills) & 16 & 16 & \\
\hline Objective & 8 & 8 & {$[21,24,32,43,47,72,124,164]$} \\
\hline Perceived & 9 & 9 & {$[23,32,66,71,100,125,142,169,170]$} \\
\hline Pavement/footpath quality & 8 & 8 & \\
\hline Objective & 2 & 2 & {$[47,124]$} \\
\hline Perceived & 6 & 6 & {$[23,24,66,121,142,163]$} \\
\hline Street lighting & 6 & 6 & \\
\hline Objective & 1 & 1 & [124] \\
\hline Perceived & 5 & 5 & {$[23,53,69,75,122]$} \\
\hline Greenery \& aesthetically pleasing scenery ${ }^{d}$ & 33 & 33 & \\
\hline Objective & 6 & 6 & {$[32,43,47,80,124,161]$} \\
\hline Perceived & 28 & 28 & $\begin{array}{l}{[20,22,23,25,32,44,48,53,61,71,75,76,79,100,122,125,127,} \\
132,137,142,147,150,154,156,159,163,169,170]\end{array}$ \\
\hline
\end{tabular}


Table 1 Characteristics of selected articles $(N=100)$ (Continued)

\begin{tabular}{|c|c|c|c|}
\hline Pollution (air) & 3 & 3 & \\
\hline Objective & 1 & 1 & [124] \\
\hline Perceived & 2 & 2 & {$[23,156]$} \\
\hline Safety & 46 & 46 & \\
\hline Objective & 7 & 7 & \\
\hline Perceived & 40 & 40 & \\
\hline Traffic/pedestrian safety & 28 & 28 & \\
\hline Objective & 4 & 4 & {$[47,72,93,124]$} \\
\hline Perceived & 24 & 24 & $\begin{array}{l}{[22-25,45,48,53,61,69,71,75,76,79,92,100,125,132,136,142,} \\
150,156,159,169,170]\end{array}$ \\
\hline Crime/personal safety ${ }^{d}$ & 41 & 41 & \\
\hline Objective & 5 & 5 & {$[43,93,124,149,157]$} \\
\hline Perceived & 37 & 37 & $\begin{array}{l}{[22,23,25,45,48,50,53,61,63,66,68,69,71,75,76,79,100,121,} \\
122,125,132-134,137,140,142-145,150,156,157,159,163,167, \\
169,170]\end{array}$ \\
\hline Moderator of environmental attribute-PA association ${ }^{\mathrm{a}}$ & 39 & 39 & \\
\hline Individual factors & 24 & 24 & $\begin{array}{l}{[20-23,44,45,48-50,59,69,70,73,77,79,100,122,125,131,144,} \\
152,155,157,159]\end{array}$ \\
\hline Socio-demographics & 16 & 16 & {$[20-23,45,49,50,69,70,73,122,125,144,152,155,157]$} \\
\hline Health status/functionality & 7 & 7 & {$[59,73,77,100,131,155,159]$} \\
\hline Psychosocial factors & 3 & 3 & {$[44,79,100]$} \\
\hline Driving status/car ownership & 2 & 2 & {$[48,73]$} \\
\hline Duration of residency & 1 & 1 & [21] \\
\hline Environmental factors & 18 & 18 & {$[19,21,25,45,46,64,66,74-76,92,100,141,146,155,160,162,168]$} \\
\hline Socioeconomic status/area-level income & 5 & 5 & {$[25,45,64,74,146]$} \\
\hline Residential density/urbanisation & 6 & 6 & {$[19,75,76,160,162,168]$} \\
\hline Infrastructure and streetscape aspects (e.g., walkability) & 3 & 3 & {$[46,92,100]$} \\
\hline Intervention & 2 & 2 & {$[66,100]$} \\
\hline Geographical scale (e.g., 400 m buffer) & 6 & 6 & {$[21,64,73,93,135,161]$} \\
\hline Tested, but unknown & 1 & 1 & [24] \\
\hline None & 61 & 61 & $\begin{array}{l}{[32,43,47,53,54,60-63,65,67,68,71,72,78,80,87,93,118-124,} \\
126-130,132-143,145,147-151,153,154,156,158,163-167,169-173]\end{array}$ \\
\hline
\end{tabular}

Notes:

${ }^{\text {a }}$ Multiple options allowed in single articles

${ }^{\mathrm{b}}$ Two articles had instances where environmental attributes were associated with different sample sizes ([53, 54]). Hence, the total number of articles added up separately is 2 units more than the total number of articles. Notably, this was adjusted for in our analysis

${ }^{\mathrm{C}}$ One article ([25]) had both objective and self-reported physical activity measures. Hence, the total number of articles is 1 unit smaller than the sum of the articles in these cases

${ }^{d}$ Multiple articles had both objective and perceived environmental measures. Hence, the total number of articles is 1, 2, or 3 unit/s smaller than the sum of the articles in these cases

the instrument used [52], or outcome measures wellestablished in the field [yes $=1$, no $=0$ ]; (5) adjustment for key socio-demographic covariates (at least age, sex, and education considered) [yes $=1$, no $=0$ ]; (6) adjustment for self-selection [yes $=1$, no $=0$ ]; (7) appropriate analytical approach - adjustment for clustering (if needed) [yes $=1 / 3$, no $=0$ ]; (8) appropriate analytical approach - accounting for distributional assumptions [yes $=1 / 3$, no $=0$ ]; (9) appropriate analytical approach
- analyses conducted and presented correctly [yes $=1 /$ 3 , no $=0]$; and (10) did not inappropriately categorise continuous environmental exposures [yes $=1$, no $=0$ ] . Higher scores reflect higher quality: 0-3.5 (low quality), 3.6-5.9 (moderate quality), and $\geq 6$ (high quality). Apart from providing descriptive information on article quality, these scores were also used as weights in the metaanalyses described below so that higher quality articles had a greater contribution to the synthesis of findings. 
To account for sample size in the meta-analyses, the following weights were assigned to findings: $0.25(\leq 100$ participants), 0.50 (101-300 participants), 1.00 (301-500 participants), 1.25 (501-1000 participants), 1.50 (10012500 participants), and 1.75 (>2500 participants). In two instances, different sample weights were applied to findings derived from the same study because of differences in sample size between objectively assessed and perceived environmental exposures [53] and between data collection periods [54]. A thorough rationale for these weights can be found elsewhere [27].

\section{Data synthesis}

Each separate positive, negative, and nil association between a built environmental attribute and PA outcome (either total PA, total MVPA, or total walking) was tallied [27] and, where appropriate, multiplied by a buffer-size or moderator-related fractional weight (see section above on 'Quantification of buffer effects and/or moderators'). All of these findings were then included into a "Total PA" outcome, which was then stratified by PA measurement type (objective or self-report). "Total walking" was considered separately and was based on findings from self-report walking only, as the majority of associations between built environmental attributes and objectively assessed walking was insufficiently examined (i.e., $<5$ findings) (Additional file 3 ). The findings related to both "Total PA" and "Total walking" were then stratified by environmental measurement type (objective or perceived).

Due to the large range of different environmental and PA measures reported in the selected articles, it was not possible to conduct a 'traditional' meta-analysis involving the estimation of pooled effect sizes and their 95\% confidence intervals. Hence, to quantitatively synthesise the findings, a meta-analytic approach was applied to define conservative estimates of $p$-values for each examined combination of environmental attribute and PA outcome [27]. These $p$-values represented the probability of observing a certain distribution of findings (e.g., 4 positive, 2 nil, and 0 negative associations) under a null hypothesis of no association. These computations were undertaken accounting for: (1) sample size and quality scores of included articles (see previous section); (2) sample size score only; (3) article quality score only; and (4) neither - with 2-4 providing a sensitivity analysis on how each of these influenced meta-analytical findings. Associations of specific built environmental attributes with PA outcomes were examined by type of PA and environmental measurement (objective and perceived) only when $\geq 3$ articles provided data on each type of measure, consistent with recommendations for meta-analyses from Cochrane's database of systematic reviews [55]. Environment-PA outcome associations totalling $<5$ separate findings were deemed as insufficiently studied to reach a robust conclusion [56].

To perform the meta-analyses, we first assigned a $\mathrm{z}$ value to each separate built environmental attribute and PA finding, specifically: 1.96 for a positive; -1.96 for a negative; and 0 for a nil finding [27]. We then calculated a summary two-tailed $p$-value using Rosenthal's approach [57], reporting a summary weighted z-value and its associated two-tailed probability value as detailed in Cerin et al.'s recent systematic review and meta-analysis of built environmental correlates of active transport [27]. For the sensitivity analysis aforementioned, we also calculated non-weighted $\mathrm{z}$ values and their associated two-tailed $p$-values. All computations were performed in a Microsoft Excel spreadsheet using algorithms developed by the authors. $P$-values were interpreted as follows: .05 to .01 - evidence of an association; <.01 strong evidence of an association; and <.001 - very strong evidence of an association [58].

All examined moderators of environment-PA associations were counted and summarised by the category of moderator tested. This included multiple factor (i.e., higher-order) moderating effects, tested formally (e.g., [59]) or not (e.g., [20]). Reporting higher-order moderating effects by moderator category resulted in findings being counted multiple times, i.e., once for each moderator category. For example, Chen and colleagues reported sex by employment status interactions, so the findings were reported twice, once under sex and once under employment status as moderators [20]. For this reason, the total number of moderating effects reported in this review is greater than the number of moderating effects reported in the articles.

\section{Results}

Of 19,005 potential articles, we fully read 530 and included 100 in our analysis - two of which were PhD theses $[60,61]$ (Fig. 1). From the 100 articles, 1553 individual associations were extracted.

\section{Characteristics of included articles}

Details of article characteristics can be found in Table 1. Cross-sectional studies accounted for $94 \%$ of articles, with five papers reporting longitudinal [61-65] and one quasi-experimental [66] findings. Almost half of all studies (46\%) were based in North America, followed by Europe (22\%), Asia (16\%), Oceania (13\%), two studies from South America [23, 24], and one pilot study from South Africa [25]. Regarding countries, the USA (36\%), Australia (13\%), the UK (10\%), and Canada (10\%) conducted the most research. Only $3 \%$ of articles specifically studied rural participants [67-69], about half researched those from urban settings (56\%), and 32\% from a mixture of both. 
Sample sizes ranged from 44 [25] to 69,253 [70], with over a third of samples (36\%) regarded as small (i.e., $\leq 300$ participants). Recruitment of neighbourhoods was stratified by key built environmental attributes in $57 \%$ of articles; urbanisation being the most prevalent $(22 \%)$, followed by area-level socioeconomic status (SES) and walkability combined (12\%), and area-level SES and urbanisation combined (10\%). Neighbourhoods were most frequently defined objectively by administrative and census areas. When buffers were applied to define neighbourhoods, a 400$500 \mathrm{~m}$ radius was the most frequently used buffer size. A 10-20 min' walk from home was the most commonly reported perceived neighbourhood definition.

Overall, $66 \%$ of articles used a validated or established PA measure. Almost three quarters of articles reported findings based on older adults' self-reported PA (74\%). The most commonly reported PA outcome was total walking (55\%). Approximately $55 \%$ of PA outcomes were operationalised as continuous measures (e.g., minutes/day) and $56 \%$ of self-report PA outcomes were measures of total walking. The most commonly reported objective PA outcome was total MVPA ( $47 \%$ of objective PA articles).

Overall, the most researched attributes were crimerelated personal safety (41\%), residential density/urbanisation (35\%), greenery and aesthetically pleasing scenery (33\%), access to/availability of parks/public open space (30\%), pedestrian-related traffic safety (28\%), and access to/availability of shops/commercial destinations (26\%). Similarly, the most investigated perceived attributes were crime-related personal safety (38\%), greenery and aesthetically pleasing scenery (28\%), pedestrian-related traffic safety $(25 \%)$, access to/ availability of parks/public open space and recreational facilities (both 15\%). The most commonly evaluated objectively assessed environmental attributes were urbanisation/residential density (21\%), and access to/ availability of shops/commercial destinations and of parks/public open space (17\% each).

Thirty-nine percent of articles investigated moderating effects on associations between built environmental attributes and total PA. At the individual level, sociodemographics were the most frequently examined moderator, and at the environmental level, residential density/urbanisation was the most frequently reported moderator. (Note: Full details of article characteristics can be found in Additional file 1).

\section{Article quality}

Only 9\% of articles were deemed of high quality, 55\% of moderate quality, and the remaining $36 \%$ of low quality. Key socio-demographic covariates (i.e., at least age, sex, and education) were adjusted for in $66 \%$ of articles; much fewer analyses adjusted for self-selection (12\%) (Table 2) [62, 69, 71-80]. Approximately three quarters of the included articles conducted appropriate analyses (76\%). (Note: Full details of article quality can be found in Additional file 3).

\section{Built environmental correlates of older adults' PA Total PA}

There was very strong evidence that neighbourhood walkability $(p<.001)$, overall access to destinations and services $(p<.001)$ and recreational facilities $(p<.001)$, and crime-related personal safety $(p<.001)$ were positively associated with older adults' total PA (Table 3).

Table 2 Summary of article quality assessment $(N=100)$

\begin{tabular}{|c|c|}
\hline Quality-assessment item [score] & $\%$ \\
\hline \multicolumn{2}{|l|}{ 1. Study design [cross-sectional: 0; longitudinal: 1; quasi-experimental: 2] } \\
\hline cross-sectional & 94 \\
\hline longitudinal & 5 \\
\hline quasi-experimental & 1 \\
\hline 2. Study areas or participant recruitment stratified by key environmental attributes [1] & 56 \\
\hline 3. Response rate $\geq 60 \%$ or sample representative of the population [1] & 32 \\
\hline 4. Physical activity measures (outcomes) valid, or well-established in the field [1] & 66 \\
\hline 5. Analyses adjusted for key socio-demographic covariates (at least age, sex, and education considered) [1] & 66 \\
\hline 6. Analysis adjusted for self-selection [1] & 12 \\
\hline 7. Analytical approach - adjustment for clustering (if needed) [1/3] & 58 \\
\hline 8. Analytical approach - accounting for distributional assumptions [1/3] & 84 \\
\hline 9. Analytical approach - analyses conducted and presented correctly [1/3] & 76 \\
\hline 10. Did not, inappropriately, categorise continuous environmental exposure/s [1] & 74 \\
\hline Total quality score [theoretical range: $0-9$ ]; mean \pm SD & $3.9 \pm 1.3$ \\
\hline
\end{tabular}


Table 3 Associations of environmental attributes/correlates with older adults' physical activity by physical activity outcomes

\begin{tabular}{|c|c|c|c|c|c|c|c|c|c|c|}
\hline \multirow[t]{2}{*}{ Environmental attribute } & \multicolumn{5}{|c|}{ Total PA } & \multicolumn{5}{|c|}{ Total walking only } \\
\hline & $P$ & $\varnothing$ & $\mathrm{N}$ & $p_{a}$ & $D_{a}$ & $P$ & $\varnothing$ & $\mathrm{N}$ & $p_{a}$ & $D_{a}$ \\
\hline Walkability & 12.33 & 6.67 & 0 & $<.001$ & $\mathbf{P}$ & 4.37 & 3.63 & 0 & .001 & $P$ \\
\hline Residential density/urbanisation & 11.53 & 33.50 & 12.97 & .394 & $\varnothing$ & 8 & 14.50 & 3.50 & .036 & $\mathbf{P}$ \\
\hline Street connectivity & 8.80 & 26.06 & 2.14 & .094 & $\varnothing$ & 5.80 & 13.20 & 2 & .185 & $\varnothing$ \\
\hline \multicolumn{11}{|l|}{ Access to/availability of destinations \& services } \\
\hline Overall access to destinations \& services & 12.55 & 38.15 & 0.50 & $<.001$ & $\mathbf{P}$ & 6.93 & 25.57 & 0.50 & .009 & $\mathbf{P}$ \\
\hline Land-use mix — destination diversity & 5.68 & 19.32 & 2 & .148 & $\varnothing$ & 1 & 8 & 2 & .439 & $\varnothing$ \\
\hline Shops/commercial & 9.96 & 57.04 & 0 & .006 & $\mathbf{P}$ & 8.58 & 23.42 & 0 & .001 & $\mathbf{P}$ \\
\hline Food outlets & 0.72 & 21.28 & 1 & .932 & $\varnothing$ & 0.72 & 6.28 & 1 & .873 & $\varnothing$ \\
\hline Government/finance services & 0.33 & 11.67 & 0 & .834 & $\varnothing$ & 0 & 6 & 0 & 1.00 & $\varnothing$ \\
\hline Education & 0.31 & 11.69 & 0 & .765 & $\varnothing$ & 0.14 & 2.85 & 0 & .826 & $\varnothing$ \\
\hline Health \& aged care & 4.61 & 26.39 & 1 & .275 & $\varnothing$ & 3.61 & 7.39 & 1 & .191 & $\varnothing$ \\
\hline Religious & 0 & 8 & 0 & 1.00 & $\varnothing$ & 0 & 1 & 0 & 1.00 & $\varnothing$ \\
\hline Public transport & 7.50 & 25.50 & 1 & .016 & $\mathbf{P}$ & 5.50 & 11.50 & 1 & .011 & $\mathbf{P}$ \\
\hline Parks/public open space & 11.29 & 47.54 & 0.17 & .002 & $\mathbf{P}$ & 6.05 & 23.78 & 0.17 & .014 & $\mathbf{P}$ \\
\hline Recreational facilities & 13.34 & 39.66 & 0 & $<.001$ & $\mathbf{P}$ & 3.07 & 15.93 & 0 & .135 & $\varnothing$ \\
\hline Social recreational facilities & 4.15 & 25.95 & 0 & .105 & $\varnothing$ & 1.50 & 10.50 & 0 & .413 & $\varnothing$ \\
\hline Other destinations & 0 & 3 & 0 & 1.00 & $\varnothing$ & - & - & - & - & - \\
\hline \multicolumn{11}{|l|}{ Infrastructure \& streetscape } \\
\hline Overall access to cycle/walk-friendly infrastructure & 1 & 9 & 0 & .612 & $\varnothing$ & 0 & 3 & 0 & 1.00 & $\varnothing$ \\
\hline Walk-friendly infrastructure & 9 & 21.49 & 1.51 & .009 & $\mathbf{P}$ & 5 & 15 & 0 & .042 & $\mathbf{P}$ \\
\hline Cycle-friendly infrastructure & 0 & 5 & 0 & 1.00 & $\varnothing$ & 0 & 3 & 0 & 1.00 & $\varnothing$ \\
\hline No physical barriers (e.g., hills) & 5 & 20.40 & 2.60 & .208 & $\varnothing$ & 2 & 14.40 & 0.60 & .384 & $\varnothing$ \\
\hline Pavement/footpath quality & 3 & 6 & 1 & .155 & $\varnothing$ & 2 & 5 & 0 & .169 & $\varnothing$ \\
\hline Street lighting & 3 & 6 & 0 & .059 & $\varnothing$ & 3 & 4 & 0 & .042 & $P$ \\
\hline Greenery \& aesthetically pleasing scenery & 13.01 & 45.49 & 0.5 & .004 & $\mathbf{P}$ & 10.51 & 19.49 & 0 & .002 & $\mathbf{P}$ \\
\hline Pollution (air) & 0 & 5 & 0 & 1.00 & $\varnothing$ & 0 & 4 & 0 & 1.00 & $\varnothing$ \\
\hline \multicolumn{11}{|l|}{ Safety } \\
\hline Traffic/pedestrian safety & 7 & 47 & 3 & .463 & $\varnothing$ & 5 & 25 & 3 & .705 & $\varnothing$ \\
\hline Crime/personal safety & 20.52 & 50.48 & 4 & $<.001$ & $\mathbf{P}$ & 10.49 & 28.01 & 2.50 & .027 & $P$ \\
\hline
\end{tabular}

Notes: ${ }^{1}$ Objective and self-report total PA (including total walking) combined. $\mathrm{P}=$ positive association; $\varnothing=$ nil association; $\mathrm{N}=$ negative association; $p=p$-value; $\mathrm{D}=$ direction of association supported by the data; subscript "a" = fully adjusted (for sample size and article quality). In bold font: statistically significant evidence of a directional association that has been sufficiently studied (i.e., $\geq 5$ findings reported on specific combinations of environmental exposure and PA variables)

Moreover, there was strong evidence of positive associations between total PA and access to both parks/public open space $(p=.002)$ and shops/commercial destinations $(p=.006)$, the presence of greenery and aesthetically pleasing scenery $(p=.004)$, and walk-friendly infrastructure $(p=.009)$. In addition, there was evidence that access to public transport was positively associated with total PA $(p=.016)$. No other significant associations were found in relation to built environmental attributes and total PA.

\section{Total walking}

We found strong evidence for positive associations between older adults' total walking and neighbourhood walkability $(p=.001)$, access to/availability of shops/ commercial destinations $(p=.001)$ and overall destinations and services $(p=.009)$ and more greenery and aesthetically pleasing scenery $(p=.002)$ (Table $3)$. We also found evidence that access to/availability of neighbourhood public transport $(p=.011)$ and parks/public open space $(p=.014)$, crime/personal safety $(p=.027)$, residential density $(p=.036)$, walk-friendly infrastructure $(p=.042)$, and street lighting $(p=.042)$ were positively associated with total walking. No significant associations were found for the remaining 15 built environmental attributes (Table 3). 


\section{Built environmental correlates of older adults' PA by measurement method}

PA measurement type (objective and self-report)

Irrespective of the PA measurement type used, neighbourhood walkability (both $p<.001$ ) and overall access to destinations and services (both $p<.01$ ) were positively associated with older adults' total PA (Table 4). Seven other positive associations between attributes of the built environment and PA were PAmeasurement dependent. Five positive associations were specific to self-reported total PA, namely: greenery and aesthetically pleasing scenery $(p=.001)$, access to shops/commercial destinations $(p=.002)$, parks/public open space $(p=.002)$, recreational facilities $(p=.002)$ and public transport $(p=.006)$. Two remaining positive associations were in relation to objectively assessed total PA only, specifically: walk- friendly infrastructure $(p=.031)$ and destination diversity (land use mix) $(p=.019)$.

\section{Environmental attribute measurement type (objective and perceived) \\ Total PA}

For nine out of 18 environmental exposures, associations with total PA differed by environmental measurement type (Table 5). For five environmental attributes, positive associations with total PA were found with perceived but not objectively assessed measures. Perceptions of crime-related personal safety $(p<.001)$, access to/availability of recreational facilities $(p<.001)$, access to/availability of parks/public open space $(p=.003)$, greenery and aesthetically pleasing scenery $(p=.003)$, and destination diversity (land-use mix) $(p=.002)$ were all positively associated with total PA. Objectively assessed

Table 4 Associations of environmental attributes/correlates with older adults' physical activity by physical activity measurement method (objective and self-report)

\begin{tabular}{|c|c|c|c|c|c|c|c|c|c|c|}
\hline \multirow[t]{3}{*}{ Environmental attribute } & \multicolumn{10}{|c|}{ Total PA } \\
\hline & \multicolumn{5}{|c|}{ Objective } & \multicolumn{5}{|c|}{ Self-report } \\
\hline & $P$ & $\varnothing$ & $\mathrm{N}$ & $\mathrm{p}_{\mathrm{a}}$ & $\mathrm{D}_{\mathrm{a}}$ & $P$ & $\varnothing$ & $\mathrm{N}$ & $\mathrm{p}_{\mathrm{a}}$ & $\mathrm{D}_{\mathrm{a}}$ \\
\hline Walkability & 5.96 & 2.04 & 0 & $<.001$ & $\mathbf{P}$ & 6.37 & 4.63 & 0 & $<.001$ & $\mathbf{P}$ \\
\hline Residential density/urbanisation & 1 & 7 & 0 & .377 & $\varnothing$ & 10.53 & 26.50 & 12.97 & .240 & $\varnothing$ \\
\hline Street connectivity & 3 & 7.86 & 0.14 & .262 & $\varnothing$ & 5.71 & 18.20 & 2 & .215 & $\varnothing$ \\
\hline \multicolumn{11}{|l|}{ Access to/availability of destinations \& services } \\
\hline Overall access to destinations $\&$ services & 3.89 & 8.31 & 0 & .005 & $\mathbf{P}$ & 8.66 & 29.84 & 0.50 & .004 & $\mathbf{P}$ \\
\hline Land-use mix-destination diversity & 3.17 & 8.83 & 0 & .019 & $\mathbf{P}$ & 2.51 & 12.49 & 2 & .884 & $\varnothing$ \\
\hline Shops/commercial & 1.38 & 26.62 & 0 & .507 & $\varnothing$ & 8.58 & 29.42 & 0 & .002 & $\mathbf{P}$ \\
\hline Food outlets & 0 & 13 & 0 & 1.00 & $\varnothing$ & 0.72 & 8.28 & 1 & .884 & $\varnothing$ \\
\hline Government/finance services & 0.34 & 5.66 & 0 & .377 & $\varnothing$ & 0 & 6 & 0 & 1.00 & $\varnothing$ \\
\hline Education & 0.17 & 6.83 & 0 & .818 & $\varnothing$ & 0.14 & 4.86 & 0 & .845 & $\varnothing$ \\
\hline Health \& aged care & 1 & 18 & 0 & .612 & $\varnothing$ & 3.61 & 8.39 & 1 & .206 & $\varnothing$ \\
\hline Religious & 0 & 5 & 0 & 1.00 & $\varnothing$ & 0 & 3 & 0 & 1.00 & $\varnothing$ \\
\hline Public transport & 1 & 12 & 0 & .520 & $\varnothing$ & 6.50 & 13.50 & 1 & .006 & $\mathbf{P}$ \\
\hline Parks/public open space & 1.75 & 14.25 & 0 & .296 & $\varnothing$ & 9.54 & 33.29 & 0.17 & .002 & $\mathbf{P}$ \\
\hline Recreational facilities & 4.29 & 16.71 & 0 & .056 & $\varnothing$ & 9.05 & 22.95 & 0 & .002 & $\mathbf{P}$ \\
\hline Social recreational facilities & 2.65 & 12.35 & 0 & .118 & $\varnothing$ & 1.50 & 13.50 & 0 & .432 & $\varnothing$ \\
\hline \multicolumn{11}{|l|}{ Infrastructure \& streetscape } \\
\hline Overall access to cycle/walk-friendly infrastructure & 1 & 5 & 0 & .529 & $\varnothing$ & 0 & 4 & 0 & 1.00 & $\varnothing$ \\
\hline Walk-friendly infrastructure & 3 & 3 & 0 & .031 & $\mathbf{P}$ & 6 & 18.49 & 1.51 & .059 & $\varnothing$ \\
\hline No physical barriers (e.g., hills) & 3 & 5 & 1 & .135 & $\varnothing$ & 2 & 15.40 & 1.60 & .631 & $\varnothing$ \\
\hline Greenery \& aesthetically pleasing scenery & 1.50 & 15 & 0.50 & .741 & $\varnothing$ & 11.51 & 30.49 & 0 & .001 & $\mathbf{P}$ \\
\hline \multicolumn{11}{|l|}{ Safety } \\
\hline Traffic/pedestrian safety & 2 & 14 & 0 & .408 & $\varnothing$ & 5 & 33 & 3 & .737 & $\varnothing$ \\
\hline Crime/personal safety & 3 & 8 & 0 & .063 & $\varnothing$ & 17.52 & 42.48 & 4 & .001 & $\mathbf{P}$ \\
\hline
\end{tabular}

Notes: $\mathrm{P}=$ positive association; $\varnothing=$ nil association; $\mathrm{N}=$ negative association; $p=p$-value; $\mathrm{D}=$ direction of association supported by the data; subscript "a" = fully adjusted (for sample size and article quality). In bold font: statistically significant evidence of a directional association that has been sufficiently studied (i.e., $\geq 5$ findings reported on specific combinations of environmental exposure and PA variables) 
Table 5 Associations of environmental attributes/correlates with older adults' physical activity by physical activity and environmental measures (objective and perceived)

\begin{tabular}{|c|c|c|c|c|c|c|c|c|c|c|}
\hline \multirow[t]{2}{*}{ Environmental attribute } & \multicolumn{5}{|c|}{ Total PA } & \multicolumn{5}{|c|}{ Total walking only } \\
\hline & $P$ & $\varnothing$ & $\mathrm{N}$ & $\mathrm{p}_{\mathrm{a}}$ & $\overline{D_{a}}$ & $\bar{P}$ & $\varnothing$ & $\mathrm{N}$ & $p_{a}$ & $D_{a}$ \\
\hline Walkability & 12.33 & 6.67 & 0 & $<.001$ & $P$ & 4.37 & 3.63 & 0 & .001 & $P$ \\
\hline Objective & 9.05 & 6.95 & 0 & $<.001$ & $P$ & - & - & - & - & - \\
\hline Perceived & 3 & 0 & 0 & .003 & $P$ & - & - & - & - & - \\
\hline Residential density/urbanisation & 11.53 & 33.5 & 12.97 & .394 & $\varnothing$ & 8 & 14.5 & 3.5 & .036 & $P$ \\
\hline Objective & 10 & 18.50 & 11.50 & .388 & $\varnothing$ & 7 & 6.50 & 3.50 & .032 & $\mathbf{P}$ \\
\hline Perceived & 1.53 & 15 & 1.47 & .855 & $\varnothing$ & 1 & 8 & 0 & .652 & $\varnothing$ \\
\hline Street connectivity & 8.71 & 26.06 & 2.14 & .094 & $\varnothing$ & 5.71 & 13.20 & 2 & .185 & $\varnothing$ \\
\hline Objective & 2.80 & 14.20 & 1 & .366 & $\varnothing$ & 1.80 & 9.20 & 1 & .543 & $\varnothing$ \\
\hline Perceived & 6 & 11.86 & 1.14 & .076 & $\varnothing$ & 4 & 4 & 1 & .210 & $\varnothing$ \\
\hline \multicolumn{11}{|l|}{ Access to/availability of destinations \& services } \\
\hline Overall access to destinations \& services & 12.55 & 38.15 & 0.5 & $<.001$ & $\mathbf{P}$ & 6.93 & 25.57 & 0.5 & .009 & $\mathbf{P}$ \\
\hline Objective & 3.76 & 12.24 & 0 & .003 & $P$ & 3.43 & 9.57 & 0 & .004 & $\mathbf{P}$ \\
\hline Perceived & 8.79 & 25.91 & 0.50 & .008 & $P$ & 3.50 & 16 & 0.50 & .277 & $\varnothing$ \\
\hline Land-use mix-destination diversity & 5.68 & 19.32 & 2 & .148 & $\varnothing$ & 1 & 8 & 2 & .439 & $\varnothing$ \\
\hline Objective & 1.17 & 10.83 & 2 & .504 & $\varnothing$ & - & - & - & - & - \\
\hline Perceived & 4.51 & 8.49 & 0 & .002 & $\mathbf{P}$ & - & - & - & - & - \\
\hline Shops/commercial & 9.96 & 57.21 & 0 & .006 & $\mathbf{P}$ & 8.58 & 23.42 & 0 & .001 & $P$ \\
\hline Objective & 8.25 & 34.75 & 0 & .006 & $\mathbf{P}$ & 7.08 & 12.92 & 0 & $<.001$ & $\mathbf{P}$ \\
\hline Perceived & 1.71 & 21.29 & 0 & .475 & $\varnothing$ & 1.50 & 10.50 & 0 & .422 & $\varnothing$ \\
\hline Food outlets & 0.72 & 21.28 & 1 & .932 & $\varnothing$ & 0.72 & 6.28 & 1 & .873 & $\varnothing$ \\
\hline Objective & 0.72 & 14.28 & 0 & .685 & $\varnothing$ & - & - & - & - & - \\
\hline Perceived & 0 & 7 & 1 & .521 & $\varnothing$ & - & - & - & - & - \\
\hline Education & 0.31 & 11.69 & 0 & .765 & $\varnothing$ & 0.14 & 2.85 & 0 & .826 & $\varnothing$ \\
\hline Objective & 0.31 & 8.69 & 0 & .727 & $\varnothing$ & - & - & - & - & - \\
\hline Perceived & 0 & 3 & 0 & 1.00 & $\varnothing$ & - & - & - & - & - \\
\hline Health \& aged care & 4.61 & 26.39 & 1 & .275 & $\varnothing$ & 3.61 & 7.39 & 1 & .191 & $\varnothing$ \\
\hline Objective & 4 & 24 & 1 & .382 & $\varnothing$ & - & - & - & - & - \\
\hline Perceived & 0.61 & 2.39 & 0 & .290 & $\varnothing$ & - & - & - & - & - \\
\hline Public transport & 7.5 & 25.6 & 1 & .013 & $P$ & 5.5 & 11.5 & 1 & .011 & $P$ \\
\hline Objective & 6.50 & 12.50 & 0 & .004 & $\mathbf{P}$ & 5.50 & 5.50 & 0 & $<.001$ & $\mathbf{P}$ \\
\hline Perceived & 1 & 13 & 1 & .918 & $\varnothing$ & 0 & 6 & 1 & .501 & $\varnothing$ \\
\hline Parks/public open space & 11.29 & 47.54 & 0.17 & .002 & $P$ & 6.05 & 23.78 & 0.17 & .014 & $P$ \\
\hline Objective & 4.42 & 28.58 & 0 & .083 & $\varnothing$ & 4.42 & 13.58 & 0 & .035 & $\mathbf{P}$ \\
\hline Perceived & 6.87 & 18.96 & 0.17 & .003 & $\mathbf{P}$ & 1.63 & 10.20 & 0.17 & .201 & $\varnothing$ \\
\hline Recreational facilities & 13.34 & 39.66 & 0 & $<.001$ & $P$ & 3.07 & 15.93 & 0 & .135 & $\varnothing$ \\
\hline Objective & 4.58 & 21.42 & 0 & .092 & $\varnothing$ & 0.29 & 6.71 & 0 & .848 & $\varnothing$ \\
\hline Perceived & 8.76 & 18.24 & 0 & $<.001$ & $\mathbf{P}$ & 2.78 & 9.22 & 0 & .050 & $\mathbf{P}$ \\
\hline Social recreational facilities & 4.15 & 25.95 & 0 & .105 & $\varnothing$ & 1.5 & 10.5 & 0 & .413 & $\varnothing$ \\
\hline Objective & 3.50 & 14.50 & 0 & .094 & $\varnothing$ & 1.50 & 4.50 & 0 & .291 & $\varnothing$ \\
\hline Perceived & 0.65 & 11.45 & 0 & .687 & $\varnothing$ & 0 & 6 & 0 & 1.00 & $\varnothing$ \\
\hline \multicolumn{11}{|l|}{ Infrastructure \& streetscape } \\
\hline Walk-friendly infrastructure & 9 & 21.49 & 1.51 & .009 & $P$ & 5 & 15 & 0 & .042 & $P$ \\
\hline
\end{tabular}


Table 5 Associations of environmental attributes/correlates with older adults' physical activity by physical activity and environmental measures (objective and perceived) (Continued)

\begin{tabular}{|c|c|c|c|c|c|c|c|c|c|}
\hline Objective & 5 & 9 & 0 & .028 & $\mathbf{P}$ & 3 & 7 & 0 & .103 \\
\hline Perceived & 4 & 12.49 & 1.51 & .137 & $\varnothing$ & 2 & 8 & 0 & .222 \\
\hline No physical barriers (e.g., hills) & 5 & 20.40 & 2.61 & .208 & $\varnothing$ & 2 & 14.40 & 0.61 & .384 \\
\hline Objective & 5 & 8.40 & 1.60 & .048 & $\mathbf{P}$ & 2 & 4.40 & 0.60 & .227 \\
\hline Perceived & 0 & 12 & 1 & .629 & $\varnothing$ & 0 & 10 & 0 & 1.00 \\
\hline Greenery \& aesthetically pleasing scenery & 13.01 & 45.49 & 0.5 & .004 & $P$ & 10.51 & 19.49 & 0 & .002 \\
\hline Objective & 3 & 18 & 0 & .252 & $\varnothing$ & 3 & 9 & 0 & .199 \\
\hline Perceived & 10.01 & 27.49 & 0.50 & .003 & $\mathbf{P}$ & 7.51 & 10.49 & 0 & $<.001$ \\
\hline \multicolumn{10}{|l|}{ Safety } \\
\hline Traffic/pedestrian safety & 7 & 47 & 3 & .463 & $\varnothing$ & 5 & 25 & 3 & .705 \\
\hline Objective & 1 & 13 & 3 & .407 & $\varnothing$ & 0 & 11 & 3 & .150 \\
\hline Perceived & 6 & 34 & 0 & .126 & $\varnothing$ & 5 & 14 & 0 & .043 \\
\hline Crime/personal safety & 20.63 & 50.58 & 3.99 & $<.001$ & $\mathbf{P}$ & 10.49 & 28.01 & 2.5 & .027 \\
\hline Objective & 4 & 5.50 & 2.50 & .510 & $\varnothing$ & 3 & 5 & 2 & .627 \\
\hline Perceived & 16.52 & 44.98 & 1.50 & $<.001$ & $\mathbf{P}$ & 7.49 & 23.01 & 0.50 & .012 \\
\hline
\end{tabular}

Notes: ${ }^{1}$ Objective and self-report total PA (including total walking) combined. $\mathrm{P}=$ positive association; $\varnothing=$ nil association; $\mathrm{N}=$ negative association; $\mathrm{p}=p$-value; $D=$ direction of association supported by the data; subscript "a" = fully adjusted (for sample size and article quality). In bold font: evidence of a difference between environmental measures of an association between a sufficiently studied exposure and PA variable (i.e., $\geq 3$ articles' reported findings on specific combinations of environmental exposure and physical activity variables)

access to/availability of shops/commercial destinations $(p=.006)$ and public transport $(p=.004)$, presence of walk-friendly infrastructure $(p=.028)$, and absence of physical environmental barriers (e.g., hills) $(p=.048)$ were all positively associated with total PA, whereas associations with these attributes were non-significant when using perceived measures.

\section{Total walking}

There were five positive PA associations with objectively measured environment variables only and four others with measures based on perceptions only. Evidence of a positive association with total walking was found for perceived measures of neighbourhood greenery and aesthetically pleasing scenery $(p<.001)$, crime/personal safety $(p=.012)$, traffic-safety $(p=.043)$, and access to/availability of recreational facilities $(p=.050)$. Regarding objectively measured environmental attributes, access to/availability of shops/commercial destinations $(p<.001)$, public transport $(p<.001)$, overall destinations and services $(p=.004)$, parks/public open space $(p=.035)$, and residential density/urbanisation $(p=.032)$ were all positively related to total walking.

\section{Sensitivity analyses}

None of the significant correlates of total PA, objective total PA or self-report total PA differed based on any adjustment (partial or none) (Additional file 4). Regarding total walking, only two significant correlates differed based on adjustment, namely: residential density/urbanisation (fully-adjusted: $p=.036$; unadjusted: $p=.055$ ) and walkfriendly infrastructure (fully-adjusted: $p=.042$; article quality-adjusted: $p=.057$ ). In addition, some built environmental attributes were significant when unadjusted, but not when taking into account sample size and/or article quality. These were street lighting (total PA and selfreport total PA), street connectivity (total walking), and crime/personal safety (objective total PA).

\section{Moderators of environment-PA associations}

Sixteen moderators of built environmental attribute-PA associations were examined in 39 articles (Additional file 5). The most frequently examined moderators by number of articles were sex (7 articles), health status/functionality (7 articles), residential density/urbanisation (6 articles), and SES/area-level income (5 articles). Buffer size (121 findings) and sex (83 findings) were the most frequently examined by estimating regression interaction terms. The direction of effects for all significant interaction terms was inconsistent (Additional file 5).

\section{Discussion}

In the last decade, world bodies have been advocating the importance of healthy ageing and the enabling role played by PA and built environments (e.g., [81]). As a result, the number of published articles on the associations between built environmental attributes and older adults' PA increased over three times since the last systematic review in 2011 [15]. Moreover, there was a greater percentage of articles from outside of North America, with 
notable increases in research conducted in Asia and Europe, which expanded the range of examined geographical settings and cultures. We undertook a systematic review and applied a meta-analytic procedure to statistically identify built environmental attributes related to total PA and total walking, stratifying by measurement method.

In general, while the findings from Van Cauwenberg and colleagues' systematic review published in 2011 were inconclusive [15], we found strong evidence of positive associations between walkability, access to destinations and services, personal safety from crime and PA. Also, while the relatively small number of articles included in Van Cauwenberg and colleagues' review [15] precluded the examination of differences in findings by measurement method, this review and meta-analysis revealed important differences in associations when using objective versus perceived measures of environmental attributes and when using self-report versus objective measures of PA. These new findings and their implications are discussed in detail below.

\section{Built environmental correlates of older adults' PA Walkability and access to destinations/services}

We found strong to very strong evidence supporting the benefits of neighbourhood walkability on total PA and walking, regardless of measurement method. Two of the three components comprising walkability were found to individually relate to PA: strong evidence supported the association between access to destinations and services and total PA, for both objective and perceived environmental and PA measurement types. Evidence was also found supporting the impact of access to destinations and services and residential density on total walking, particularly when these attributes were measured objectively. Our findings highlight the importance of having local neighbourhood destinations for older adults to not only walk to and walk around, but to also engage in other types of PA. Furthermore, local destinations may provide a location for social activity and engagement, potentially reducing risk of social isolation and loneliness [82].

Although easier access to destinations and services tend to be highly correlated with greater residential density [83], our findings suggest that walking may be the only type of PA positively related to residential density. High levels of residential density may not be conducive to other forms of active transport, such as cycling. One study has found that Flemish older adults living in urban areas were less likely to cycle everyday than those living in semi-urban (i.e., less dense) areas [84]. While walking is the most popular type of PA that older adults participate in [9], cycling is also a popular PA mode in European countries such as the Netherlands, Denmark, and Germany, where cycling levels remain high even among older people [85]. Future research examining the differential influence of residential density on different types of PA as well as identifying the optimal threshold of density for supporting all types of PA will be important for informing planning policy and practice [86].

In terms of access to specific types of destinations in the neighbourhood, we found evidence supporting shops and commercial destinations, public transport, parks and public open space, and recreational facilities as possible facilitators of PA. No evidence was found for the seven other destination types examined. Overall, this is in line with the work of others who highlight that certain types of destinations may be more conducive to higher PA levels than other destination types [15, 27].

Shops/commercial destinations and public transport, particularly for objectively assessed measurement types, were positively associated with total walking and total PA, specifically self-reported measures of total PA. The importance of shops and commercial destinations for PA is consistent with findings highlighting that shopping is the most prevalent reason for older adults leaving their homes [87], and thus an important part of daily life. Therefore, ensuring neighbourhoods have ease of access to shops means that health-enhancing levels of PA can be incorporated into daily living. Availability and access to public transport not only facilitates PA levels but has the potential to also reduce car dependence [88] with co-benefits of environmental sustainability [89]. For older adults especially, access to public transport enables those who are not confident with driving or no longer able to drive to still travel outside of home, thus maintaining their mobility and reducing risk of loneliness [90].

We found strong to very strong evidence for parks and public open space and recreational facilities as correlates of total PA, particularly for self-reported types of measurement. This is consistent with findings in adults [91]. When comparing environmental measurement methods, evidence was found for positive associations between total PA and perceived, but not objectively assessed, access to parks, public open space and recreational facilities. Access to parks and public open space was also found to be positively associated with total walking. However, when comparing the environmental measurement type, it was the objectively assessed measures showing a positive association with total walking, not perceptions. Here, it should be noted that most of the objectively assessed positive findings were from studies based in Portland, USA [64, 92, 93], a city renowned for its walk-friendliness and management of parks in the presence of urban growth [94, 95]. Having accessible parks and public open space and recreational facilities in local areas may be beneficial beyond PA, as green spaces and visual cues of nature in parks may impart further 
psychological benefits on individuals [96, 97]. Moreover, both destinations provide an opportunity for fostering social connectedness/activities (e.g., a walk with friends in a park and a game of squash at a recreational facility).

\section{Infrastructure and streetscape}

Pedestrian-friendly infrastructure, particularly when measured objectively, was found to be positively associated with both total PA and total walking. This reflects qualitative [98] and experimental research [99] findings highlighting the importance of pavements/footpaths and other infrastructure, such as benches for resting, for older adults' PA. Ensuring the provision of walkfriendly infrastructure, especially along routes to destinations within the neighbourhood, may be particularly pertinent. It is plausible that the relationship between walk-friendly infrastructure and PA may differ based on physical functionality. However, we identified only one study that had examined this, finding no difference in the associations [100].

We found evidence supporting a positive association between street lighting and total walking only. This highlights the importance of providing street lighting along pedestrian infrastructure so that its use is not dependent on the time of day. For older adults especially, ensuring neighbourhoods are well-lit at night may also contribute to a heightened sense of safety from crime [98]. This is because street lighting helps contribute to natural surveillance by allowing pedestrians to be seen.

We found no evidence of an association between pavement/footpath quality and PA. This is in contrast to qualitative research findings indicating quality of infrastructure to be particularly pertinent in facilitating PA among older adults [98, 99, 101]. Our findings may be explained by the diversity of measures used and/or lack of clear definition of pavement/footpath quality. For example, what constituted 'footpath quality' ranged from "curb quality" (objectively assessed) [47] to "quality and maintenance of sidewalks" (as perceived by study participants) [24].

Strong evidence supported the role of greenery and aesthetically pleasing scenery on levels of total PA (especially self-reported measurement types) and total walking. These findings are in line with recent research highlighting the importance of green, clean, and attractive neighbourhoods and streetscapes in facilitating PA $[98,102]$. When stratifying by environmental measurement type, only perceived measures were found to be significant. Beyond facilitating PA, it is plausible that there are synergistic benefits of streetscape trees and vegetation, for example, in reducing urban heat island effect [103] and air pollution [104] - environmental factors linked with premature mortality [105] and global disease burden [106]. Following design principles of 'tactical urbanism', which are low cost interventions to make areas more attractive and pedestrian-friendly [107], environmental modifications such as planting trees and flora are micro-scale interventions that can be more easily implemented than macro-level interventions to street design and layout.

\section{Safety}

Safety from crime, especially when perceived measures were used, was found to be positively associated with total PA (primarily self-reported measures) and total walking. This adds to the evidence base as previous research in older adults has mostly shown inconsistent findings $[31,108]$. Our findings are in line with the notion that perceptions of crime have more influence on behaviour (e.g., leaving the home) than objective crime rates [109]. This speaks in favour of interventions aimed at positively changing perceptions of safety (when appropriate) and encouraging older people to get out of home. This may be particularly important as the frequency of daily out of home trips is predictive of PA participation in this demographic [87].

Overall, we found no evidence to support the relationship between traffic-related safety and total PA and total walking. However, when only perceived measures of traffic safety were considered, there was evidence of a positive association with total walking only. It is possible that older adults may have no choice other than participating in walking near heavy neighbourhood traffic because they do not own a car and/or have limited access to public transport [73]. It may be that a substantial amount of walking and PA in older adults comes from actively travelling to and from destination-rich areas where traffic is typically heavy [27].

\section{Differences in built environmental correlates by type of PA measurement method}

We found more significant environmental correlates for self-reported PA than for objectively measured PA. One reason for this may relate to common method bias associated with self-reported PA and environmental attributes - systematic error variance introduced by measurement methods that do not accurately assess the constructs they represent and may be due to factors such as social desirability [110]. Another reason may be that the environmental attributes measured in these studies primarily influence walking behaviours that may be more easily measured by self-reports than by accelerometry. An additional reason may relate to issues with the accelerometry-based operationalisation of older adults' MVPA. Sixteen of the 28 reviewed articles reporting objective PA findings used accelerometer cut-points and half of those applied an MVPA cut-point of 1952 accelerometer counts per min derived for adults [111]. As 
older adults have a lower MVPA cut-point due to lower resting metabolic rates [112], using the adult accelerometer cut-point likely resulted in lower estimates of MVPA, potentially masking associations. To accurately classify different intensities of older adults' PA, future research using objectively assessed PA should be underpinned by appropriate cut-points.

\section{Differences in built environmental correlates by type of environmental measurement method}

Overall, there were numerous differences in the associations between built environmental attributes and total PA and walking, based on type of environmental measure. Attributes that can be classed within the functional (e.g., pedestrian infrastructure) and destination domains in Pikora's framework tended to be significantly related to PA when objectively assessed [113]. In contrast, those attributes that fall within the safety and aesthetics domains were associated with PA when perceived measures were used. This may be explained by attributes within safety and aesthetics domains being more subjective in their interpretation and thus depend on perceptions that may vary greatly between individuals. Attributes related to function and destinations are more objective and, hence, are associated with lower levels of interpersonal differences in perceptions (e.g., a pavement is either present or it is not).

Effects were generally stronger for associations between the perceived environment and PA, which is consistent with previous research [114]. Unlike the objective environment, perceptions of the same neighbourhood environment can greatly differ across individuals due to differences in socio-demographics (e.g., socioeconomic status), preference, experience, culture and/or amount of walking in the neighbourhood [30]. Regular walkers may have more accurate perceptions of their local environments. Moreover, perceived measures often define neighbourhood in terms of time to reach a destination (e.g., 10-20 min' walk from home) [40, 41], rather than set distances (e.g., objective $400 \mathrm{~m}$ home-centred buffers), and therefore may be more closely aligned with the individual and their own definition of 'neighbourhood'.

\section{Implications for future research and planning policy/ practice}

Socio-ecological models of health behaviour underpin the majority of research undertaken in the built environment and PA field. One of the key tenets of this approach is its emphasis on the importance of behaviour specificity [12], and for PA this means considering the domain in which PA was accrued. While taking a behavioural perspective allows for the pathways or mechanisms through which the built environment influences PA to be understood, it is possible that built environmental attributes may relate differently to different behaviours [115]. Instead, a public health perspective examining built environmental attributes associated with total PA focuses on the identifications of environmental attributes enabling health-enhancing levels of PA, which is accrued across all domains. Notably, nearly all built environmental correlates of older adults' total PA were also identified as being environmental correlates of either active transport [27] and/or leisure-time PA [116], thus explaining the behavioural pathways through which the built form impacts on total levels of PA. There was one exception, however, with crime/personal safety being positively associated with total PA, but no evidence found for a relationship with either active transport [27] or leisuretime PA [116]. Other behavioural or psychosocial factors may explain the associations between crime/ personal safety and total PA. Given the medium to strong evidence of these associations, it is especially important for future research to unpack the mechanisms through which crime/personal safety relates to total health-enhancing PA in order to better inform the implementation of suitable interventions. For example, a better understanding of fear of crime and assessment of the emotional rather than cognitive response to crime may be warranted [108]. Moderators of the relationship between safety and PA that warrant further consideration may include self-efficacy and physical functioning/capacity [117].

\section{Research design issues}

Longitudinal and quasi-experimental studies are needed to establish causal relationships between the built environment and PA. Insofar as possible, future research designs would also benefit from assessing and adjusting for residential self-selection to account for biases at the individual level (e.g., an older adult who enjoys PA or chooses to live near a park) and thus enabling, to a certain extent, the controlling of reverse causation. The findings of this review may help inform researchers involved with natural experiments on what environmental attributes to measure, given the environmental manipulation itself will be out of their control.

Better quality research may also come from conceptuallydriven choices of built environmental attributes and validated PA measures. Where accelerometer cut-points and the classification of older adults' PA intensities are concerned, it is important that the thresholds for moderate intensity activity are appropriate (e.g., 1013 counts per min [112]). Applying suggestions such as these also allows for the possibility of pooling data across countries. For example, there has been evidence of curvilinearity related to perceived access to destinations and services and objectively assessed MVPA in a multi-country study of adults [31]. This finding was only possible because of the use of 
comparable environmental exposure and PA outcome measures across a large range of diverse geographical locations combined with a high variability in exposures across countries (another issue that future research may care to address). Thus, the multi-country pooling of data based on valid, comparable measures are needed to address issues surrounding limited variability in environmental exposures and non-linear associations between exposures and PA outcomes. Other statistical analysis decisions such as adjusting for key socio-demographic covariates (i.e., age, sex, and education), and not categorising continuous environmental measures would contribute to improving the quality of future research designs.

Strengths and limitations of this review and meta-analysis This systematic review and meta-analysis has several strengths. It addressed publication bias by including both peer-reviewed scientific articles and grey literature. It provided a quantitative synthesis of associations based on non-standardised environmental and PA measurement instruments and stratified findings by measurement types. It incorporated an extensive article quality assessment into the meta-analytical procedure and, therefore, adjusted the synthesis of evidence for study methodology quality. Limitations include: (1) not accounting for potentially correlated findings from the same article; (2) an inability to account for potential moderating effects of neighbourhood size and definition; (3) using a meta-analytic method that relied on statistical significance testing rather than effect size estimates and, thus, likely underestimating the evidence of environmentPA associations; and (4) including only articles published in English.

\section{Conclusions}

Safe, walkable, and aesthetically pleasing neighbourhoods, with access to destinations and services, specifically, recreational facilities, parks/public open space, shops/commercial destinations and public transport facilitated older adults' participation in PA, beyond domain-specificity. However, PA correlates were not consistent across different PA and environmental measurement types. Future research should consider these differences in findings and identify the mechanisms underlying them. Future studies should also strive to undertake higher quality research by implementing longitudinal research designs, adjusting for residential self-selection, conceptually-driven choosing of built environmental attributes, using validated PA measures (including, where necessary, appropriate accelerometer cut-points), pooling data from different countries based on valid standardised measures, adjusting for key socio-demographic covariates, and not inappropriately categorising continuous environmental measures.

\section{Additional files}

Additional file 1: Table S1. Reviewed total physical activity articles $(N=100)$ - Information. (DOCX $286 \mathrm{~kb})$

Additional file 2: Table S3. Reviewed total physical activity articles $(N=100)$ - Quality assessment. (DOCX $106 \mathrm{~kb}$ )

Additional file 3: Table S2. Associations between built environmental attributes and older adults' objectively measured walking. (DOCX $16 \mathrm{~kb}$ )

Additional file 4: Table S4. Meta-analytic results of significance of associations between built environmental correlates of older adults' PA by outcome and type of adjustment for article characteristics. (DOCX 19 kb)

Additional file 5: Table S5. Overview of moderating effects examined in the association between environmental attributes and older adults' total PA. (DOCX $214 \mathrm{~kb}$ )

\section{Abbreviations}

MVPA: Moderate- to vigorous-intensity PA; PA: Physical activity; PhD: Doctor of Philosophy; PRISMA: Preferred Reporting Items for Systematic Reviews and Meta-Analyses; SD: Standard deviation; UK: United Kingdom of Great Britain and Northern Ireland; USA: United States of America

\section{Acknowledgements}

This work has been undertaken as a collaborative effort under the umbrella of the Council on Environment and Physical Activity-Older Adults working group, chaired by Ester Cerin.

\section{Funding}

David William Barnett is supported by an international postgraduate research scholarship. Ester Cerin is supported by an Australian Research Council Future Fellowship (FT3 140100085). Jelle Van Cauwenberg is supported by a postdoctoral fellowship of the Research Foundation Flanders (FWO, 1211117N). The funding bodies had no role in the design of the review and meta-analysis, interpretation of data, nor writing of the manuscript.

\section{Availability of data and materials}

All information generated and analysed in this systematic review and metaanalysis are included in this published article and its supplementary information files (Additional files 1, 2, 3, 4 and 5).

\section{Authors' contributions}

All authors conceptualised the systematic review. EC developed the review protocol and the meta-analytical approach. DWB conducted the meta-analyses and AN verified its validity. DWB extracted the data from the included articles, drafted the manuscript, and supplementary materials. AB, AN, and JVC verified the validity of the extracted data from the included articles. JVC and AN searched the grey literature. All authors conducted searches, contributed to the screening of article eligibility, revised the manuscript for intellectual content, and approved the final manuscript.

Ethics approval and consent to participate Not applicable.

\section{Consent for publication}

Not applicable.

\section{Competing interests}

The authors declare that they have no competing interests.

\section{Publisher's Note}

Springer Nature remains neutral with regard to jurisdictional claims in published maps and institutional affiliations.

\section{Author details}

${ }^{1}$ Institute for Health and Ageing, Australian Catholic University, Level 6, 215 Spring Street, Melbourne, VIC 3000, Australia. ${ }^{2}$ Department of Public Health, Ghent University, De Pintelaan 185, 9000 Ghent, Belgium. ${ }^{3}$ Research Foundation Flanders, Egmontstraat 5, 1000 Brussels, Belgium. ${ }^{4}$ School of Public Health, The University of Hong Kong, 7 Sassoon Road, Pokfulam, Hong Kong, Special Administrative Region, China. ${ }^{5}$ Baker IDI Heart and Diabetes Institute, 75 Commercial Road, Melbourne, VIC 3004, Australia. 
Received: 15 May 2017 Accepted: 31 July 2017

Published online: 07 August 2017

\section{References}

1. World Health Organisation. Global Health and aging. Geneva: World Health Organisation; 2011.

2. Fries JF. Successful aging - an emerging paradigm of gerontology. Clin Geriatr Med. 2002;18:371-82.

3. Nelson ME, Rejeski WJ, Blair SN, Duncan PW, Judge JO, King AC, Macera CA, Castaneda-Sceppa C. Physical activity and public health in older adults: recommendation from the American College of Sports Medicine and the American Heart Association. Med Sci Sports Exerc. 2007;39:1435-45.

4. Vogel T, Brechat PH, Lepretre PM, Kaltenbach G, Berthel M, Lonsdorfer J. Health benefits of physical activity in older patients: a review. Int J Clin Pract. 2009;63:303-20.

5. Chodzko-Zajko WJ, Proctor DN, Fiatarone Singh MA, Minson CT, Nigg CR, Salem GJ, Skinner JS. Exercise and physical activity for older adults. Med Sci Sports Exerc. 2009;41:1510-30.

6. Canadian Health Measures Survey: Percentage attaining selected physical activity criteria, by age group and sex, household population aged 20 to 79 years, Canada, march 2007 to 2009. http://www.statcan.gc.ca/pub/82-003-x/ 2011001/article/11396/tbl/tbl5-eng.htm. Accessed 31 Oct 2016.

7. Troiano RP, Berrigan D, Dodd KW, Masse LC, Tilert T, McDowell M. Physical activity in the United States measured by accelerometer. Med Sci Sports Exerc. 2008;40:181-8.

8. Haskell WL, Lee IM, Pate RR, Powell KE, Blair SN, Franklin BA, Macera CA, Heath GW, Thompson PD, Bauman A. Physical activity and public health: updated recommendation for adults from the American College of Sports Medicine and the American Heart Association. Med Sci Sports Exerc. 2007; 39:1423-34.

9. Cunningham GO, Michael YL. Concepts guiding the study of the impact of the built environment on physical activity for older adults: a review of the literature. Am J Health Promot. 2004;18:435-43.

10. Morris JN, Hardman AE. Walking to health. Sports Med. 1997;23:306-32.

11. Stokols D. Establishing and maintaining healthy environments - toward a social ecology of health promotion. Am Psychol. 1992;47:6-22.

12. Sallis JF, Cervero RB, Ascher W, Henderson KA, Kraft MK, Kerr J. An ecological approach to creating active living communities. Annual Review of Public Health Volume. 2006;27:297-322.

13. Topinkova E. Aging, disability and frailty. Ann Nutr Metab. 2008;52:6-11.

14. Rantakokko M, Manty M, Iwarsson S, Tormakangas T, Leinonen R, Heikkinen E, Rantanen T. Fear of moving outdoors and development of outdoor walking difficulty in older people. J Am Geriatr Soc. 2009:57:634-40.

15. Van Cauwenberg J, De Bourdeaudhuij I, De Meester F, Van Dyck D, Salmon J, Clarys P, Deforche B. Relationship between the physical environment and physical activity in older adults: a systematic review. Health \& Place. 2011;17: 458-69.

16. Cerin E, Chan KW, Macfarlane DJ, Lee KY, Lai PC. Objective assessment of walking environments in ultra-dense cities: development and reliability of the environment in Asia scan tool-Hong Kong version (EAST-HK). Health \& Place. 2011;17:937-45.

17. Millington C, Thompson CW, Rowe D, Aspinall P, Fitzsimons C, Nelson N, Mutrie N. Sparcoll: development of the Scottish Walkability assessment tool (SWAT). Health \& Place. 2009:15:474-81.

18. Rodrigue JP, Comtois C, Slack B. The geography of transport systems. Abingdon: Routledge; 2009.

19. Carvalho Sampaio RA, Sewo Sampaio PY, Yamada M, Ogita M, Arai H. Urban-rural differences in physical performance and health status among older Japanese community-dwelling women. Journal of Clinical Gerontology and Geriatrics. 2012;3:127-31.

20. Chen TA, Lee JS, Kawakubo K, Watanabe E, Mori K, Kitaike T, Akabayashi A. Features of perceived neighborhood environment associated with daily walking time or habitual exercise: differences across gender, age, and employment status in a community-dwelling population of Japan. Environ Health Prev Med. 2013;18:368-76.

21. Hanibuchi T, Kawachi I, Nakaya T, Hirai H, Kondo K. Neighborhood built environment and physical activity of Japanese older adults: results from the Aichi Gerontological evaluation study (AGES). BMC Public Health. 2011;11:657.

22. Inoue S, Ohya Y, Odagiri Y, Takamiya T, Kamada M, Okada S, Oka K, Kitabatake Y, Nakaya T, Sallis JF, Shimomitsu T. Perceived neighborhood environment and walking for specific purposes among elderly Japanese. Journal of Epidemiology. 2011;21:481-90.

23. Salvador EP, Reis RS, Florindo AA. Practice of walking and its association with perceived environment among elderly Brazilians living in a region of low socioeconomic level. Int J Behav Nutr Phys Act. 2010;7

24. Gomez LF, Parra DC, Buchner D, Brownson RC, Sarmiento OL, Pinzon JD, Ardila M, Moreno J, Serrato M, Lobelo F. Built environment attributes and walking patterns among the elderly population in Bogota. Am J Prev Med. 2010;38:592-9.

25. Kolbe-Alexander TL, Pacheco K, Tomaz SA, Karpul D, Lambert EV. The relationship between the built environment and habitual levels of physical activity in south African older adults: a pilot study. BMC Public Health. 2015; 15:518.

26. Gebel K, Ding D, Foster C, Bauman AE, Sallis JF. Improving current practice in reviews of the built environment and physical activity. Sports Med. 2015; 45:297-302.

27. Cerin E, Nathan A, van Cauwenberg J, Barnett DW, Barnett A. The neighbourhood physical environment and active travel in older adults: a systematic review and meta-analysis. Int J Behav Nutr Phys Act. 2017;14:15.

28. Davison KK, Lawson CT. Do attributes in the physical environment influence children's physical activity? A review of the literature. Int J Behav Nutr Phys Act. 2006;3

29. Lamb KE, White SR. Categorisation of built environment characteristics: the trouble with tertiles. Int J Behav Nutr Phys Act. 2015;12:19.

30. Cerin E, Cain KL, Oyeyemi AL, Owen N, Conway TL, Cochrane T, Van Dyck D, Schipperijn J, Mitas J, Toftager M, et al. Correlates of agreement between accelerometry and self-reported physical activity. Med Sci Sports Exerc. 2016:48:1075-84.

31. Cerin E, Cain KL, Conway TL, Van Dyck D, Hinckson E, Schipperijn J, De Bourdeaudhuij I, Owen N, Davey RC, Hino AAF, et al. Neighborhood environments and objectively measured physical activity in 11 countries. Med Sci Sports Exerc. 2014;46:2253-64.

32. Michael Y, Beard T, Choi DS, Farquhar S, Carlson N. Measuring the influence of built neighborhood environments on walking in older adults. J Aging Phys Act. 2006;14:302-12.

33. Weden MA, Carpiano RA, Robert SA. Subjective and objective neighborhood characteristics and adult health. Soc Sci Med. 2008;66:1256-70.

34. Hoehner CM, Ramirez LKB, Elliott MB, Handy SL, Brownson RC. Perceived and objective environmental measures and physical activity among urban adults. Am J Prev Med. 2005;28:105-16.

35. McCormack GR, Cerin E, Leslie E, Du Toit L, Owen N. Objective versus perceived walking distances to destinations - correspondence and predictive validity. Environ Behav. 2008;40:401-25.

36. Shephard RJ. Limits to the measurement of habitual physical activity by questionnaires. Br J Sports Med. 2003;37:197-206.

37. Panter J, Griffin S, Ogilvie D. Correlates of reported and recorded time spent in physical activity in working adults: results from the commuting and health in Cambridge study. PLoS One. 2012;7

38. Cerin E, Barnett D, Barnett A, Nathan A, Van Cauwenberg J. Neighbourhood built environment and total physical activity in older adults: a systematic review and meta-analysis. PROSPERO. 2016;2016:CRD42016051227.

39. Moher D, Liberati A, Tetzlaff J, Altman DG, Grp P. Preferred reporting items for systematic reviews and meta-analyses: the PRISMA statement. PLoS Med. 2009;6:6.

40. Brownson RC, Hoehner CM, Day K, Forsyth A, Sallis JF. Measuring the built environment for physical activity: state of the science. Am J Prev Med. 2009, 36:S99-S123.e112.

41. Spittaels H, Foster C, Oppert J-M, Rutter H, Oja P, Sjostrom M, De Bourdeaudhuij I. Assessment of environmental correlates of physical activity: development of a European questionnaire. Int J Behav Nutr Phys Act. 2009;6(1):39.

42. Boone-Heinonen J, Guilkey DK, Evenson KR, Gordon-Larsen P. Residential self-selection bias in the estimation of built environment effects on physical activity between adolescence and young adulthood. Int J Behav Nutr Phys Act. 2010;7:70.

43. Kerr J, Carlson JA, Sallis JF, Rosenberg D, Leak CR, Saelens BE, Chapman JE, Frank LD, Cain KL, Conway TL, King AC. Assessing health-related resources in senior living residences. J Aging Stud. 2011;25:206-14.

44. Carlson JA, Sallis JF, Conway TL, Saelens BE, Frank LD, Kerr J, Cain KL, King AC. Interactions between psychosocial and built environment factors in explaining older adults' physical activity. Prev Med. 2012;54:68-73. 
45. Carlson JA, Bracy NL, Sallis JF, Millstein RA, Saelens BE, Kerr J, Conway TL, Frank LD, Cain KL, King AC. Sociodemographic moderators of relations of neighborhood safety to physical activity. Med Sci Sports Exerc. 2014;46: 1554-63.

46. Bracy NL, Millstein RA, Carlson JA, Conway TL, Sallis JF, Saelens BE, Kerr J, Cain $\mathrm{KL}$, Frank LD, King AC. Is the relationship between the built environment and physical activity moderated by perceptions of crime and safety? Int J Behav Nutr Phys Act. 2014;11(1):24.

47. Cain KL, Millstein RA, Sallis JF, Conway TL, Gavand KA, Frank LD, Saelens BE, Geremia CM, Chapman J, Adams MA, et al. Contribution of streetscape audits to explanation of physical activity in four age groups based on the microscale audit of pedestrian streetscapes (MAPS). Soc Sci Med. 2014;116:82-92.

48. Ding D, Sallis JF, Norman GJ, Frank LD, Saelens BE, Kerr J, Conway TL, Cain K, Hovell MF, Hofstetter CR, King AC. Neighborhood environment and physical activity among older adults: do the relationships differ by driving status? J Aging Phys Act. 2014;22:421-31.

49. Nathan A, Pereira G, Foster S, Hooper P, Saarloos D, Giles-Corti B. Access to commercial destinations within the neighbourhood and walking among Australian older adults. Int J Behav Nutr Phys Act. 2012;9:133.

50. Jefferis BJ, Sartini C, Lee IM, Choi M, Amuzu A, Gutierrez C, Casas JP, Ash S, Lennnon LT, Wannamethee SG, Whincup PH. Adherence to physical activity guidelines in older adults, using objectively measured physical activity in a population-based study. BMC Public Health. 2014;14(1):382.

51. Ogilvie D, Foster CE, Rothnie $H$, Cavill N, Hamilton V, Fitzsimons CF, Mutrie N. Interventions to promote walking: systematic review. BMJ. 2007;334:1204.

52. Forsen L, Loland NW, Vuillemin A, Chinapaw MJ, van Poppel MN, Mokkink LB, van Mechelen W, Terwee CB. Self-administered physical activity questionnaires for the elderly: a systematic review of measurement properties. Sports Med. 2010;40:601-23.

53. Wang Z, Lee $C$. Site and neighborhood environments for walking among older adults. Health \& Place. 2010;16:1268-79.

54. Spinney JEL, Millward H. Active living among older Canadians: a time-use perspective over 3 decades. J Aging Phys Act. 2014;22:103-13.

55. Davey J, Turner RM, Clarke MJ, Higgins JP. Characteristics of meta-analyses and their component studies in the Cochrane database of systematic reviews: a cross-sectional, descriptive analysis. BMC Med Res Methodol. 2011;11:160

56. Higgins JPT, Thompson SG, Spiegelhalter DJ. A re-evaluation of randomeffects meta-analysis. Journal of the Royal Statistical Society Series A: Statistics in Society. 2009;172:137-59.

57. Rosenthal R. New directions for methodology of social and behavioural science: quantitative assessment of research domains. San Francisco: JosseyBass; 1980.

58. Bland M. An introduction to medical Statisitcs. 3rd ed. Oxford: University Press; 2000.

59. Cerin E, Rainey-Smith SR, Ames D, Lautenschlager NT, Macaulay SL, Fowler C, Robertson JS, Rowe CC, Maruff P, Martins RN, et al. Associations of neighborhood environment with brain imaging outcomes in the AIBL cohort. Alzheimers Dement. 2016;13:388-98.

60. Asawachaisuwikrom W. Predictors of physical activity among older Thai adults. Austin: Doctoral, University of Texas, at Austin, Faculty of the Graduate School; 2001

61. De Melo LL. Perceived neighbourhood environment and health-related outcomes among older adults. Winnipeg: Doctoral thesis, University of Manitoba, Faculty of Graduate Studies; 2013.

62. Gauvin L, Richard L, Kestens Y, Shatenstein B, Daniel M, Moore SD, Mercille $\mathrm{G}$, Payette $\mathrm{H}$. Living in a well-serviced urban area is associated with maintenance of frequent walking among seniors in the VoisiNuAge study. J Gerontol B Psychol Sci Soc Sci. 2012;67:76-88.

63. Li FZ, Fisher KJ, Brownson RC. A multilevel analysis of change in neighborhood walking activity in older adults. J Aging Phys Act. 2005;13:145-59.

64. Michael YL, Perdue LA, Orwoll ES, Stefanick ML, Marshall LM. Physical activity resources and changes in walking in a cohort of older men. Am J Public Health. 2010;100:654-60.

65. Lee IM, Ewing R, Sesso HD. The built environment and physical activity levels: the Harvard alumni health study. Am J Prev Med. 2009;37:293-8.

66. Thompson CW, Curl A, Aspinall P, Alves S, Zuin A. Do changes to the local street environment alter behaviour and quality of life of older adults? The 'DIY Streets' intervention. Br J Sports Med. 2012;48:1059-65.
67. Grant-Savela SD. Active living among older residents of a rural naturally occurring retirement community. J Appl Gerontol. 2010;29:531-53.

68. Shores KA, West ST, Theriault DS, Davison EA. Extra-individual correlates of physical activity attainment in rural older adults. J Rural Health. 2009;25:211-8.

69. Wilcox S, Bopp M, Oberrecht L, Kammermann SK, McElmurray CT. Psychosocial and perceived environmental correlates of physical activity in rural and older african american and white women. J Gerontol B Psychol Sci Soc Sci. 2003;58:329-37.

70. James P, Troped PJ, Hart JE, Joshu CE, Colditz GA, Brownson RC, Ewing R, Laden F. Urban sprawl, physical activity, and body mass index: Nurses' health study and Nurses' health study II. Am J Public Health. 2013;103:369-75.

71. Nathan A, Wood L, Giles-Corti B. Perceptions of the built environment and associations with walking among retirement village residents. Environ Behav. 2014;46:46-69.

72. Nathan A, Wood L, Giles-Corti B. Exploring socioecological correlates of active living in retirement village residents. J Aging Phys Act. 2014;22:1-15.

73. Cerin E, Zhang CJP, Barnett A, Sit CHP, Cheung MMC, Johnston JM, Lai PC, Lee RSY. Associations of objectively-assessed neighborhood characteristics with older adults' total physical activity and sedentary time in an ultradense urban environment: findings from the ALECS study. Health \& Place. 2016:42:1-10

74. Van Cauwenberg J, Van Holle V, De Bourdeaudhuij I, Van Dyck D, Deforche B. Neighborhood walkability and health outcomes among older adults: the mediating role of physical activity. Health \& Place. 2016;37:16-25.

75. Lee HS, Park EY. Associations of neighborhood environment and walking in Korean elderly women: a comparison between urban and rural dwellers. Asian Women. 2015;31:1-21.

76. Maisel JL. Impact of older adults' neighborhood perceptions on walking behavior. J Aging Phys Act. 2016;24:247-55.

77. Macniven R, Pye V, Merom D, Milat A, Monger C, Bauman A, van der Ploeg $H$. Barriers and enablers to physical activity among older Australians who want to increase their physical activity levels. J Phys Act Health. 2014;11: 1420-9.

78. Pan SY, Cameron C, DesMeules M, Morrison H, Craig CL, Jiang X. Individual, social, environmental, and physical environmental correlates with physical activity among Canadians: a cross-sectional study. BMC Public Health. 2009; $9(1): 21$

79. Sniehotta FF, Gellert P, Witham MD, Donnan PT, Crombie IK, McMurdo MET. Psychological theory in an interdisciplinary context: psychological, demographic, health-related, social, and environmental correlates of physical activity in a representative cohort of community-dwelling older adults. Int J Behav Nutr Phys Act. 2013;10:106-16.

80. Zhang Y, Li Y, Liu Q, Li C. The built environment and walking activity of the elderly: an empirical analysis in the Zhongshan metropolitan area, China. Sustain For. 2014;6:1076-92.

81. World Health Organisation. World report on ageing and health. Geneva: World Health Organisation; 2015.

82. Van den Berg P, Arentze T, Timmermans H. A multilevel analysis of factors influencing local social interaction. Transportation. 2015;42:807-26.

83. Glazier RH, Creatore MI, Weyman JT, Fazli G, Matheson Fl, Gozdyra P, Moineddin R, Shriqui VK, Booth GL. Density, destinations or both? A comparison of measures of walkability in relation to transportation behaviors, obesity and diabetes in Toronto. Canada Plos One. 2014;9:e85295.

84. Van Cauwenberg J, Clarys P, De Bourdeaudhuij I, Van Holle V, Verte D, De Witte N, De Donder L, Buffel T, Dury S, Deforche B. Physical environmental factors related to walking and cycling in older adults: the Belgian aging studies. BMC Public Health. 2012;12(1):142.

85. Pucher J, Buehler R. Making cycling irresistible: lessons from the Netherlands, Denmark and Germany. Transp Rev. 2008;28:495-528.

86. Christiansen LB, Cerin E, Badland H, Kerr J, Davey R, Troelsen J, van Dyck D, Mitas J, Schofield G, Sugiyama T, et al. International comparisons of the associations between objective measures of the built environment and transport-related walking and cycling: IPEN adult study. Journal of Transport \& Health. 2016:3:467-78.

87. Davis MG, Fox KR, Hillsdon M, Coulson JC, Sharp DJ, Stathi A, Thompson JL. Getting out and about in older adults: the nature of daily trips and their association with objectively assessed physical activity. Int J Behav Nutr Phys Act. 2011;8:9.

88. Shoham DA, Dugas LR, Bovet P, Forrester TE, Lambert EV, Plange-Rhule J, Schoeller DA, Brage S, Ekelund U, Durazo-Arvizu RA, et al. Association of car ownership and physical activity across the spectrum of human 
development: modeling the epidemiologic transition study (METS). BMC Public Health. 2015;15:173.

89. Sallis JF, Spoon C, Cavill N, Engelberg JK, Gebel K, Parker M, Thornton CM, Lou D, Wilson AL, Cutter CL, Ding D. Co-benefits of designing communities for active living: an exploration of literature. Int J Behav Nutr Phys Act. 2015;12

90. Van den Berg P, Kemperman A, de Kleijn B, Borgers A. Ageing and Ioneliness: the role of mobility and the built environment. Travel Behaviour and Society. 2016;5:48-55.

91. Van Holle V, Deforche B, Van Cauwenberg J, Goubert L, Maes L, Van de Weghe N, De Bourdeaudhuij I. Relationship between the physical environment and different domains of physical activity in European adults: a systematic review. BMC Public Health. 2012;12

92. Li FZ, Fisher KJ, Brownson RC, Bosworth M. Multilevel modelling of built environment characteristics related to neighbourhood walking activity in older adults. J Epidemiol Community Health. 2005:59:558-64.

93. Nagel CL, Carlson NE, Bosworth M, Michael YL. The relation between neighborhood built environment and walking activity among older adults. Am J Epidemiol. 2008;168:461-8.

94. Song Y, Knaap G-J. Measuring urban form: is Portland winning the war on sprawl? J Am Plan Assoc. 2004;70:210-25.

95. Abbott C. Planning a Sustainable City: the promise and performance of Portland's urban growth boundary. In: Squires G, editor. Urban sprawl: causes, consequences and policy responses. Washington D.C.: Urban Institute Press; 2002. p. 207-35.

96. Takano T, Nakamura K, Watanabe M. Urban residential environments and senior citizens' longevity in megacity areas: the importance of walkable green spaces. J Epidemiol Community Health. 2002;56:913-8.

97. Grinde B, Patil GG. Biophilia: does visual contact with nature impact on health and well-being? Int J Environ Res Public Health. 2009;6:2332-43.

98. Moran M, Van Cauwenberg J, Hercky-Linnewiel R, Cerin E, Deforche B, Plaut P. Understanding the relationships between the physical environment and physical activity in older adults: a systematic review of qualitative studies. Int J Behav Nutr Phys Act. 2014;11(1):79.

99. Van Cauwenberg J, De Bourdeaudhuij I, Clarys P, Nasar J, Salmon J, Goubert L, Deforche B. Street characteristics preferred for transportation walking among older adults: a choice-based conjoint analysis with manipulated photographs. Int J Behav Nutr Phys Act. 2016;13(1):6.

100. Merom D, Gebel K, Fahey P, Astell-Burt T, Voukelatos A, Rissel C, Sherrington C. Neighborhood walkability, fear and risk of falling and response to walking promotion: the easy steps to health 12-month randomized controlled trial. Preventive Medicine Reports. 2015;2:704-10.

101. Strath $S$, Isaacs $R$, Greenwald MJ. Operationalizing environmental indicators for physical activity in older adults. J Aging Phys Act. 2007;15:412-24.

102. Gong Y, Gallacher J, Palmer S, Fone D. Neighbourhood green space, physical function and participation in physical activities among elderly men: the Caerphilly prospective study. Int J Behav Nutr Phys Act. 2014; 11:40.

103. Dimoudi A, Nikolopoulou M. Vegetation in the urban environment: microclimatic analysis and benefits. Energy and Buildings. 2003;35:69-76.

104. Nowak DJ, Crane DE, Stevens JC. Air pollution removal by urban trees and shrubs in the United States. Urban Forestry and Urban Greening. 2006;4: 115-23.

105. Luber G, McGeehin M. Climate change and extreme heat events. Am J Prev Med. 2008;35:429-35.

106. Cohen AJ, Brauer M, Burnett R, Anderson HR, Frostad J, Estep K, Balakrishnan K, Brunekreef B, Dandona L, Dandona R, et al. Estimates and 25-year trends of the global burden of disease attributable to ambient air pollution: an analysis of data from the global burden of diseases study 2015. Lancet. 2017:389:1907-18.

107. Lydon M, Garcia A. Tactical urbanism: short-term action for long-term change. New York City: Springer; 2015.

108. Foster S, Giles-Corti B. The built environment, neighborhood crime and constrained physical activity: an exploration of inconsistent findings. Prev Med. 2008:47:241-51.

109. Hale C. Fear of crime: a review of the literature. International Review of Victimology. 1996:4:79-150.

110. Podsakoff PM, MacKenzie SB, Lee J-Y, Podsakoff NP. Common method biases in behavioral research: a critical review of the literature and recommended remedies. J Appl Psychol. 2003;88:879-903.

111. Freedson PS, Melanson E, Sirard J. Calibration of the computer science and applications, inc. accelerometer. Med Sci Sports Exerc. 1998;30:777-81.
112. Barnett A, Van Den Hoek D, Barnett D, Cerin E. Measuring moderateintensity walking in older adults using the ActiGraph accelerometer. BMC Geriatr. 2016;16(1):211.

113. Pikora T, Giles-Corti B, Bull F, Jamrozik K, Donovan R. Developing a framework for assessment of the environmental determinants of walking and cycling. Soc Sci Med. 2003;56:1693-703.

114. Gebel K, Bauman A, Owen N. Correlates of non-concordance between perceived and objective measures of walkability. Ann Behav Med. 2009;37: 228-38.

115. KRB G, Viswanath K. Health behavior and health education: theory, research, and practice. San Francisco: Jossey-Bass; 2008.

116. Van Cauwenberg JNA, Barnett A, Barnett DW, Cerin E. Relationships between neighbourhood physical environmental attributes and older adults' leisure-time physical activity: a systematic review and meta-analysis. Under review. 2017;5:S11.

117. Won J, Lee C, Forjuoh SN, Ory MG. Neighborhood safety factors associated with older adults' health-related outcomes: a systematic literature review. Soc Sci Med. 2016;165:177-86.

118. Aird RL, Buys L. Active aging: exploration into self-ratings of "being active," out-of-home physical activity, and participation among older Australian adults living in four different settings. Journal of Aging Research. 2015;2015: 501823

119. Arnadottir SA, Gunnarsdottir ED, Lundin-Olsson L. Are rural older Icelanders less physically active than those living in urban areas? A population-based study. Scandinavian Journal of Public Health. 2009;37:409-17.

120. Baceviciene M, Alisauskas J. Perceived constraints on exercise in the group of the elderly: a pilot study. Central European Journal of Medicine. 2013;8: 689-95.

121. Bird S, Radermacher H, Feldman S, Sims J, Kurowski W, Browning C, Thomas S. Factors influencing the physical activity levels of older people from culturally-diverse communities: an Australian experience. Ageing Soc. 2009; 29:1275-94.

122. Bird SR, Radermacher H, Sims J, Feldman S, Browning C, Thomas S. Factors affecting walking activity of older people from culturally diverse groups: an Australian experience. J Sci Med Sport. 2010;13:417-23.

123. Böcker $L$, van Amen $P$, Helbich $M$. Elderly travel frequencies and transport mode choices in greater Rotterdam, the Netherlands. Transportation. 2016: $1-22$.

124. Cerin E, Mellecker R, Macfarlane DJ, Barnett A, Cheung M-C, CHP S, Chan WM. Socioeconomic status, neighborhood characteristics, and walking within the neighborhood among older Hong Kong Chinese. Journal of Aging and Health. 2013;25:1425-44.

125. Chad KE, Reeder BA, Harrison EL, Ashworth NL, Sheppard SM, Schultz SL, Bruner BG, Fisher KL, Lawson JA. Profile of physical activity levels in community-dwelling older adults. Med Sci Sports Exerc. 2005;37:1774-84.

126. Chaudhury H, Campo M, Michael Y, Mahmood A. Neighbourhood environment and physical activity in older adults. Soc Sci Med. 2016;149:104-13.

127. De Melo LL, Menec V, Porter MM, Ready AE. Personal factors, perceived environment, and objectively measured walking in old age. J Aging Phys Act. 2010;18:280-92.

128. Espinel PT, Chau JY, van der Ploeg HP, Merom D. Older adults' time in sedentary, light and moderate intensity activities and correlates: application of Australian time use survey. J Sci Med Sport. 2015;18:161-6.

129. Fox KR, Hillsdon M, Sharp D, Cooper AR, Coulson JC, Davis M, Harris R, McKenna J, Narici M, Stathi A, Thompson JL. Neighbourhood deprivation and physical activity in UK older adults. Health \& Place. 2011;17:633-40.

130. Frank L, Kerr J, Rosenberg D, King A. Healthy aging and where you live: community design relationships with physical activity and body weight in older Americans. J Phys Act Health. 2010;7:S82-90.

131. Gallagher NA, Clarke PJ, Ronis DL, Cherry CL, Nyquist L, Gretebeck KA. Influences on neighborhood walking in older adults. Res Gerontol Nurs. 2012;5:238-50.

132. Hall KS, McAuley E. Individual, social environmental and physical environmental barriers to achieving 10000 steps per day among older women. Health Educ Res. 2010;25:478-88.

133. Han BH, Sadarangani T, Wyatt LC, Zanowiak JM, Kwon SC, Trinh-Shevrin C, Lee L, Islam NS. Correlates of physical activity among middle-aged and older Korean Americans at risk for diabetes. J Nurs Scholarsh. 2016;48:48-57.

134. Hannon L 3rd, Sawyer P, Allman RM. Housing, the neighborhood environment, and physical activity among older African Americans. Journal of Health Disparities Research and Practice. 2012;5:27-41. 
135. Hirsch JA, Winters M, Ashe MC, Clarke PJ, McKay HA. Destinations that older adults experience within their GPS activity spaces: relation to objectively measured physical activity. Environ Behav. 2016;48:55-77.

136. Jongeneel-Grimen B, Busschers W, Droomers M, van Oers HAM, Stronks K, Kunst AE. Change in neighborhood traffic safety: does it matter in terms of physical activity? PLoS One. 2013;8

137. Jongeneel-Grimen B, Droomers M, van Oers HM, Stronks K, Kunst AE. The relationship between physical activity and the living environment: a multilevel analyses focusing on changes over time in environmental factors. Health \& Place. 2014;26:149-60.

138. Julien D, Richard L, Gauvin L, Fournier M, Kestens Y, Shatenstein B, Daniel M, Mercille G, Payette $H$. Transit use and walking as potential mediators of the association between accessibility to services and amenities and social participation among urban-dwelling older adults: insights from the VoisiNuAge study. Journal of Transport \& Health. 2015;2:35-43.

139. Kaur J, Kaur G, Ho BK, Yao WK, Salleh M, Lim KH. Predictors of physical inactivity among elderly Malaysians: recommendations for policy planning Asia Pac J Public Health. 2015;27:314-22.

140. King AC, Toobert D, Ahn D, Resnicow K, Coday M, Riebe D, Garber CE, Hurtz S, Morton J, Sallis JF. Perceived environments as physical activity correlates and moderators of intervention in five studies. Am J Health Promot. 2006; 21:24-35.

141. King WC, Brach JS, Belle S, Killingsworth R, Fenton M, Kriska AM. The relationship between convenience of destinations and walking levels in older women. Am J Health Promot. 2003;18:74-82.

142. Koh PP, Leow BW, Wong YD. Mobility of the elderly in densely populated neighbourhoods in Singapore. Sustainable Cities and Society. 2015;14:126-32.

143. Latham K, Williams MM. Does neighborhood disorder predict recovery from mobility limitation? Findings from the health and retirement study. Journal of Aging and Health. 2015;27:1415-42.

144. Li Y, Kao D, Dinh TQ. Correlates of neighborhood environment with walking among older Asian Americans. Journal of Aging and Health. 2015;27:17-34.

145. Lim K, Taylor L. Factors associated with physical activity among older people-a population-based study. Prev Med. 2005:40:33-40.

146. Lotfi S, Koohsari MJ. Neighborhood walkability in a city within a developing country. Journal of Urban Planning and Development-Asce. 2011;137:402-8.

147. McKee G, Kearney PM, Kenny RA. The factors associated with self-reported physical activity in older adults living in the community. Age Ageing. 2015; 44:586-92.

148. McMurdo MET, Argo I, Crombie IK, Feng Z, Sniehotta FF, Vadiveloo T, Witham MD, Donnan PT. Social, environmental and psychological factors associated with objective physical activity levels in the over 65s. PLoS One. 2012;7

149. Mendes de Leon CFC, K. A, Bienias JL, Barnes LL, Skarupski KA, Scherr PA, Evans DA. Neighborhood social cohesion and disorder in relation to walking in community-dwelling older adults: a multilevel analysis. Journal of Aging and Health. 2009;21:155-71.

150. Morris KS, McAuley E, Motl RW. Self-efficacy and environmental correlates of physical activity among older women and women with multiple sclerosis. Health Educ Res. 2008:23:744-52.

151. Mowen A, Orsega-Smith E, Payne L, Ainsworth B, Godbey G. The role of park proximity and social support in shaping park visitation, physical activity, and perceived health among older adults. J Phys Act Health. 2007;4:167-79.

152. Murtagh EM, Murphy MH, Murphy NM, Woods C, Nevill AM, Lane A. Prevalence and correlates of physical inactivity in community-dwelling older adults in Ireland. PLoS One. 2015;10:e0118293.

153. Nathan A, Wood L, Giles-Corti B. Examining correlates of self-reported and objectively measured physical activity among retirement village residents. Australasian Journal on Ageing. 2014;33:250-6.

154. Pelclová J, Frömel K, Bláha L, Zając-Gawlak I, Tlučáková L. Neighborhood environment and walking for transport and recreation in central European older adults. Acta Universitatis Palackianae Olomucensis Gymnica. 2012;42:49-56.

155. Perry CK, Herting JR, Berke EM, Nguyen HQ, Moudon AV, Beresford SAA, Ockene JK, Manson JE, LaCroix AZ. Does neighborhood walkability moderate the effects of intrapersonal characteristics on amount of walking in post-menopausal women? Health \& Place. 2013;21:39-45.

156. Persson A, While A. Physical activity among older people and related factors. Health Educ J. 2012;71:144-53.

157. Piro FN, Noess O, Claussen B. Physical activity among elderly people in a city population: the influence of neighbourhood level violence and self perceived safety. J Epidemiol Community Health. 2006;60:626-32.
158. Procter-Gray E, Leveille SG, Hannan MT, Cheng J, Kane K, Li W. Variations in community prevalence and determinants of recreational and utilitarian walking in older age. Journal of Aging Research. 2015;2015:382703.

159. Satariano WA, Ivey SL, Kurtovich E, Kealey M, Hubbard AE, Bayles CM, Bryant LL, Hunter RH, Prohaska TR. Lower-body function, neighborhoods, and walking in an older population. Am J Prev Med. 2010;38:419-28.

160. Sewo Sampaio PY, Ito E, Carvalho Sampaio RA. The association of activity and participation with quality of life between Japanese older adults living in rural and urban areas. Journal of Clinical Gerontology and Geriatrics. 2013;4:51-6.

161. Shin W-H, Kweon B-S, Shin W-J. The distance effects of environmental variables on older African American women's physical activity in Texas. Landsc Urban Plan. 2011;103:217-29.

162. Sugiyama T, Thompson CW. Older people's health, outdoor activity and supportiveness of neighbourhood environments. Landsc Urban Plan. 2007; 83:168-75.

163. Sugiyama T, Thompson CW, Alves S. Associations between neighborhood open space attributes and quality of life for older people in Britain. Environ Behav. 2009;41:3-21

164. Tanaka T, Tanaka K, Suyama K, Honda S, Senjyu H, Kozu R. Comparison of objective physical activity, muscle strength, and depression among community-dwelling older women living in sloped versus non-sloped environments. J Nutr Health Aging. 2016:520-4.

165. Thompson JL, Bentley G, Davis M, Coulson J, Stathi A, Fox KR. Food shopping habits, physical activity and health-related indicators among adults aged $\geq 70$ years. Public Health Nutr. 2011;14:1640-9.

166. Timmermans EJ, Schaap LA, Visser M, van der Ploeg HP, Wagtendonk AJ, van der Pas S, Deeg DJ. The association of the neighbourhood built environment with objectively measured physical activity in older adults with and without lower limb osteoarthritis. BMC Public Health. 2015;15:710.

167. Towne SD Jr, Won J, Lee S, Ory MG, Forjuoh SN, Wang S, Lee C. Using walk score $^{T M}$ and neighborhood perceptions to assess walking among middleaged and older adults. J Community Health. 2016;41:977-88.

168. Troped PJ, Starnes HA, Puett RC, Tamura K, Cromley EK, James P, BenJoseph E, Melly SJ, Laden F. Relationships between the built environment and walking and weight status among older women in three U.S. states. J Aging Phys Act. 2014;22:114-25.

169. Tsunoda K, Tsuji T, Kitano N, Mitsuishi Y, Yoon J-Y, Yoon J, Okura T. Associations of physical activity with neighborhood environments and transportation modes in older Japanese adults. Prev Med. 2012;55:113-8.

170. Van Holle V, Van Cauwenberg J, Gheysen F, Van Dyck D, Deforche B, Van de Weghe N, De Bourdeaudhuij I. The association between Belgian older adults' physical functioning and physical activity: what is the moderating role of the physical environment? PLoS One. 2016;11:e0148398.

171. Villanueva K, Knuiman M, Nathan A, Giles-Corti B, Christian H, Foster S, Bull F. The impact of neighborhood walkability on walking: does it differ across adult life stage and does neighborhood buffer size matter? Health \& Place. 2014;25:43-6

172. Winters M, Barnes R, Venners S, Ste-Marie N, McKay H, Sims-Gould J, Ashe MC. Older adults' outdoor walking and the built environment: does income matter? BMC Public Health. 2015;15:1-8.

173. Yeom HA, Jung D, Choi M. Adherence to physical activity among older adults using a geographic information system: Korean National Health and nutrition examinations survey IV. Asian Nursing Research. 2011;5:118-27.

\section{Submit your next manuscript to BioMed Central and we will help you at every step:}

- We accept pre-submission inquiries

- Our selector tool helps you to find the most relevant journal

- We provide round the clock customer support

- Convenient online submission

- Thorough peer review

- Inclusion in PubMed and all major indexing services

- Maximum visibility for your research

Submit your manuscript at www.biomedcentral.com/submit 